\title{
Amyloidogenic Protein-Membrane Interactions: Mechanistic Insight from Model Systems
}

Sara M. Butterfield and Hilal A. Lashuel*

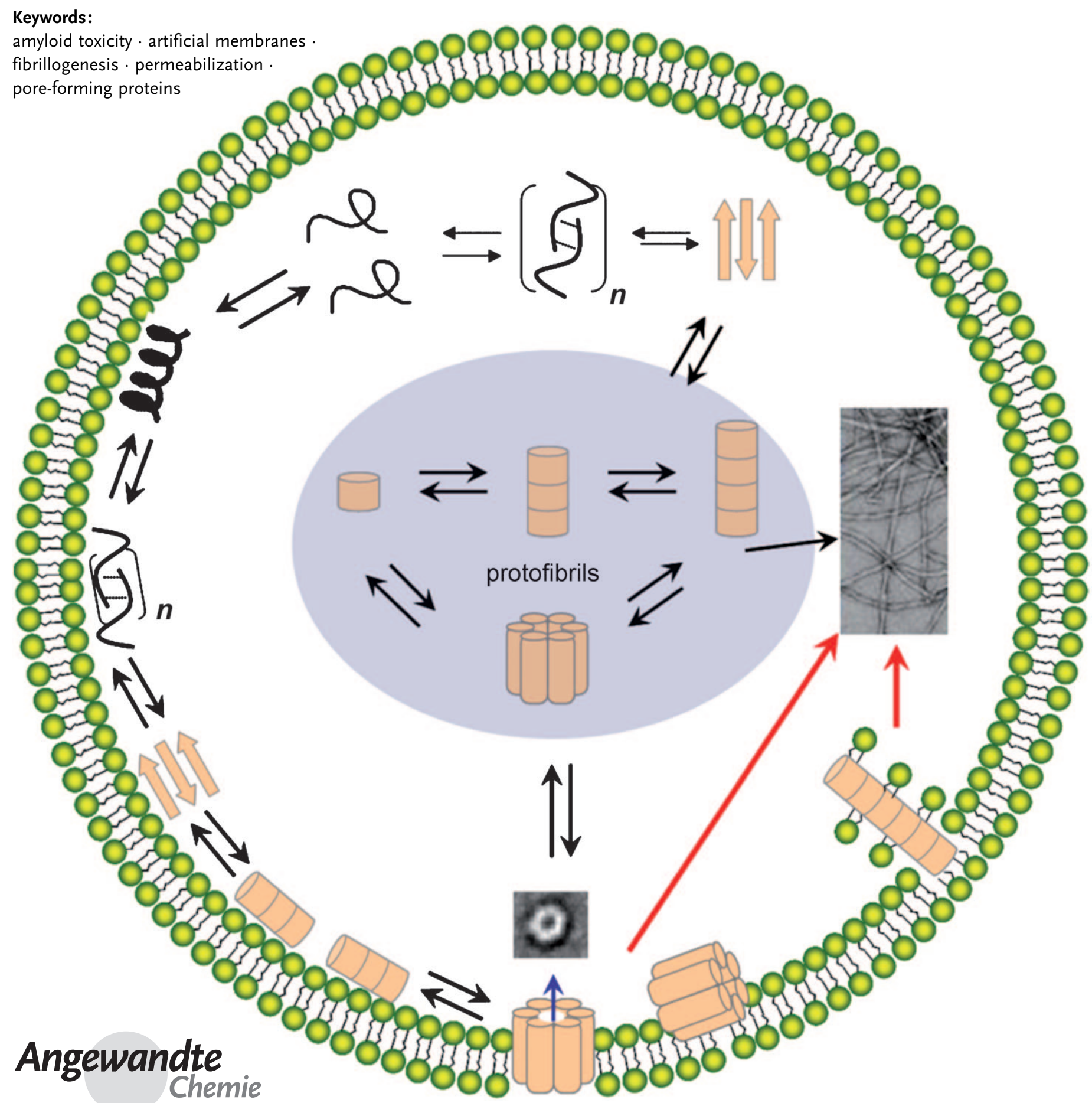


The interactions with cell membranes. Binding events between amyloidogenic proteins and membranes result in mutally disruptive structural perturbations, which are associated with toxicity. Membrane surfaces promote the conversion of amyloid-forming proteins into toxic aggregates, and amyloidogenic proteins, in turn, compromise the structural integrity of the cell membrane. Recent studies with artificial model membranes have highlighted the striking resemblance of the mechanisms of membrane permeabilization of amyloid-forming proteins to those of pore-forming toxins and antimicrobial peptides.

\section{Introduction}

Alzheimer's disease (AD), Parkinson's disease (PD), type II diabetes mellitus, and several other age-related neurodegenerative and systemic disorders are protein-misfolding diseases characterized by the accumulation of insoluble protein deposits. These protein deposits are composed of $\beta$-sheet-rich fibrillar aggregates, or amyloids, and are made of a single protein. The amyloid- $\beta(\mathrm{A} \beta)$ peptide is the main constituent of the senile plaques in the brains of $\mathrm{AD}$ patients. ${ }^{[1]}$ Similarly, $\alpha$-synuclein fibrils are the primary constituents of the fibrillar neuronal inclusions, or Lewy bodies, observed in the brains of PD patients. ${ }^{[2]}$ Furthermore, the pathology of type II diabetes mellitus is characterized by an extracellular accumulation of amyloid plaques that are composed mainly of islet amyloid polypeptide (IAPP) near pancreatic $\beta$ cells. $^{[3]}$

Amyloidogenic proteins, including A $\beta$, IAPP, and $\alpha$ synuclein, are produced as soluble proteins and are converted into lower-molecular-weight soluble oligomers of $\beta$ sheets (such as dimers, trimers) in a nucleation-dependant manner. Further protein accumulation forms higher-molecular-weight protofibrillar oligomers, which are then converted into the insoluble fibrils that make up amyloid plaques (Scheme 1). Low-molecular-weight and higher-molecular-weight oligomers are collectively referred to as prefibrillar aggregates.

Increasing evidence supports the hypothesis that the prefibrillar intermediates, rather than the final mature amyloid fibrils themselves, are the primary toxic species which trigger pathological processes that lead to disease ${ }^{[4]}$ It has been demonstrated that oligomeric forms of $A \beta$ are toxic to primary neurons, inhibit hippocampal long-term potentiation, and cause memory impairment in rat or mouse models. ${ }^{[5]}$ These results have spawned what is referred to as the "toxicoligomer hypothesis". ${ }^{[4 c, 6]}$ The similar morphological features and toxic properties shared by protofibrillar aggregates derived from various amyloid-forming proteins suggest that common mechanisms of aggregation and toxicity underlie the pathogenesis of amyloid-related diseases. ${ }^{[7]}$ However, it is not likely that a single mechanism is solely responsible for the onset of neurodegeneration, but rather a combination of many. Nonetheless, increasing evidence indicates the cell membrane as a common target for oligomeric forms of amyloidogenic proteins. ${ }^{[7,8]}$

\section{From the Contents}

\begin{tabular}{l} 
1. Introduction \\
$\begin{array}{l}\text { 2. Protein Misfolding and Fibril } \\
\text { Formation at Membrane } \\
\text { Surfaces }\end{array}$ \\
$\begin{array}{l}\text { 3. Mechanisms of Amyloid- } \\
\text { Mediated Membrane } \\
\text { Permeabilization }\end{array}$ \\
$\begin{array}{l}\text { 4. Membrane Model Systems and } \\
\text { Experimental Tools for } \\
\text { Elucidating the Mechanisms of } \\
\text { Protein-Induced Membrane } \\
\text { Permeabilization }\end{array}$ \\
$\begin{array}{l}\text { 5. Summary and Outlook } \\
5636\end{array}$ \\
\hline
\end{tabular}

Biophysical investigations and mechanistic studies with simplified model membrane systems have contributed to our fundamental understanding of the interactions between amyloid-forming proteins and membranes. Remarkably, these investigations have demonstrated that the interactions between amyloidogenic proteins and membranes result in mutually disruptive structural perturbations of both the protein and the membrane. ${ }^{[9]}$ On one hand, membrane surfaces, depending on their chemical composition, can serve as catalytic sites that promote the misfolding and aggregation of bound amyloidogenic proteins (Scheme 1). ${ }^{[10]}$ On the other hand, amyloidogenic proteins disrupt membrane structural integrity by enabling the unregulated passage of small molecules and ions through the membrane (Scheme 1).$^{[a, b, 11]}$ Extrapolation of these findings to the situation in vivo indicates the loss of membrane critical ion gradients and cell-membrane depolarization in response to interactions with oligomeric structures of amyloidogenic proteins. The exact mechanisms for membrane permeabilization by amyloidogenic proteins have not yet been fully uncovered, but experimental results have led to several proposed mechanistic models. Experiments have supported evidence for transmembrane oligomeric pore structures reminiscent of those of pore-forming toxins, ${ }^{[76,12]}$ nonspecific binding of amyloid oligomers to the membrane surface, ${ }^{[4 a, b]}$ and detergent-like membrane dissolution by amyloid fibrils growing on the membrane surface ${ }^{[13]}$ (Scheme 1).

Despite the growing number of reports linking the toxicity of amyloid proteins with their disruption of membrane integrity, there remains a knowledge gap regarding the molecular-level details by which amyloid-forming proteins

[*] Dr. S. M. Butterfield, Prof. H. A. Lashuel

Laboratory of Molecular Neurobiology and Neuroproteomics Swiss Federal Institute of Technology Lausanne (EPFL) SV-BMI-LMNN AI2351, 1015 Lausanne (Switzerland) E-mail: hilal.lashuel@epfl.ch 


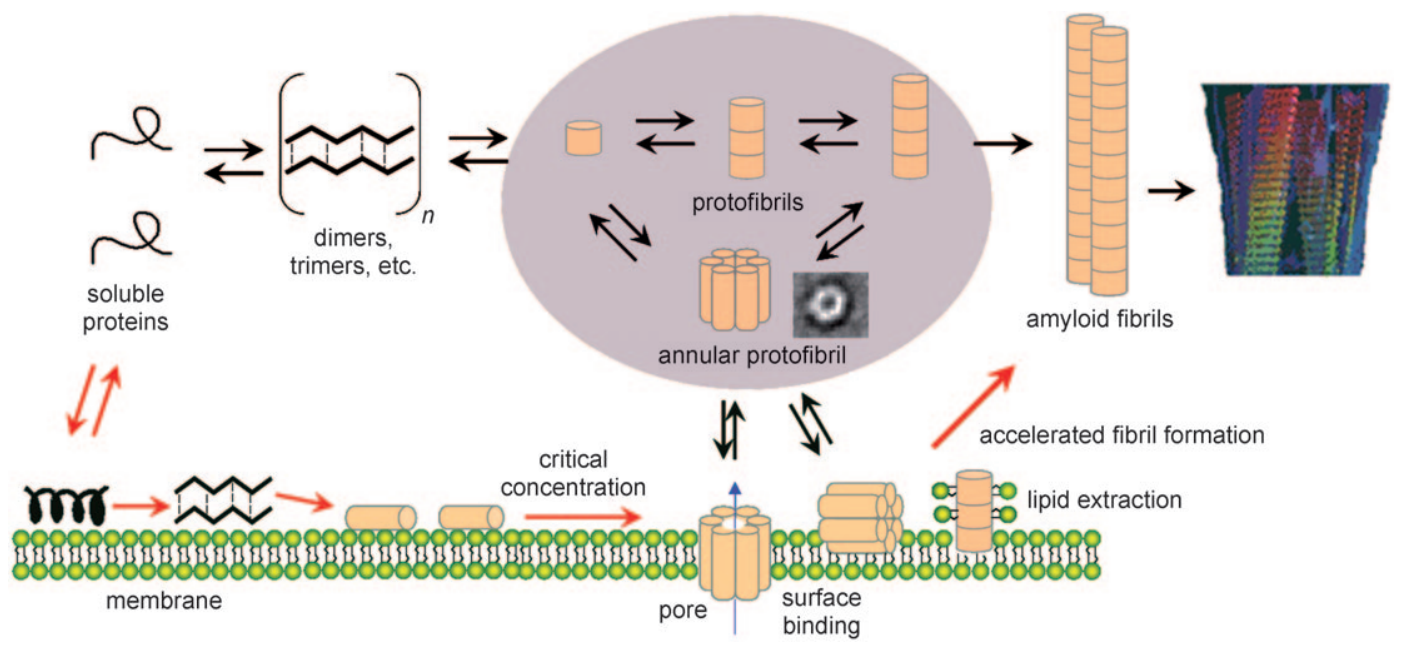

Scheme 1. Interconnectivity between amyloid formation and membrane disruption. Top: The process of amyloid-fibril formation. Amyloid formation involves the misfolding of soluble proteins into $\beta$-sheet oligomers, which further aggregate into protofibrils, including ringlike annular protofibrils, and then into amyloid fibrils. Bottom: The role of membranes in amyloid formation and toxicity. Soluble proteins bind to membrane surfaces with a shift to an $\alpha$-helix structure. The accumulation of proteins on the surface of the membrane induces their oligomerization into $\beta$ sheet aggregates. When a critical threshold concentration is reached, a transmembrane pore (annular protofibril) develops in the membrane and enables the leakage of membrane contents. As other possible or coexistent mechanisms, annular protofibrils formed in solution may insert into the membrane, undefined prefibrillar aggregates may bind to the membrane surface and induce membrane thinning, and lipids may be extracted from the membrane and incorporated into the developing fibril in a detergent-like process.

act on the membrane and induce membrane permeabilization. Other questions remain concerning the variation of the permeabilization mechanism depending on the protein oligomeric state and identity, as well as the remarkable participation of the membrane itself in the formation of the protein oligomeric species which induce its structural breakdown.

The aim of this Review is to highlight and summarize recent literature on model systems that have contributed insight into the mechanisms by which: 1) membrane surfaces influence the folding, oligomerization, and fibril formation of amyloidogenic proteins, and 2) how these oligomeric protein structures disrupt membrane structural integrity. We present the current mechanistic models explaining amyloid-induced membrane permeabilization, including experimental results that support or disfavor each model. A third aim of this Review is to highlight the various membrane model systems and experimental tools available for probing the interactions between amyloidogenic proteins and membranes to investigate the key mechanistic aspects which underlie cytotoxicity.

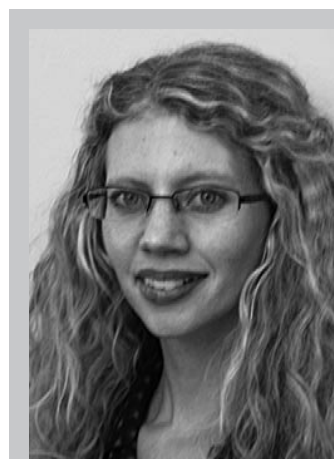

Sara M. Butterfield received her PhD in Bioorganic Chemistry from UNC Chapel Hill in 2004. She is currently a research fellow in Prof. Lashuel's group, where her research interests include the development of chemical and physical methods for controlling protein misfolding to enable elucidation of the molecular basis of neurodegenerative diseases.

This Review focuses primarily on the results obtained for A $\beta, \alpha$-synuclein, and IAPP in recent years (2006-2009). These proteins were chosen on the basis of the wealth of important recent discoveries, which may be relevant to the activity of other amyloid-forming proteins, as well as for their prominent role in Alzheimer's disease, Parkinson's disease, and type II diabetes mellitus. Less detailed results on the prion proteins are also presented, particularly those that emphasize mechanistic analogies with the amyloid-forming proteins. The studies presented are primarily based on simplified model membranes as scaffolds, in which the complex interplay of the molecular mechanisms that underlie these mutual structural perturbations may be elucidated in a relatively controlled and systematic manner.

It is our hope that this Review will provide a comprehensive overview of current knowledge on the mechanism of action of amyloidogenic proteins on membranes and will stimulate further research in this area to fill the knowledge gap. An improved mechanistic understanding of the toxic activity of amyloid-forming proteins on membrane systems is

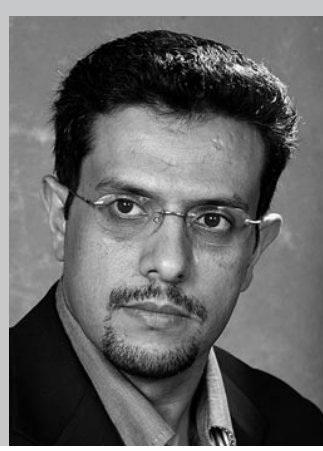

Hilal A. Lashuel obtained his PhD from Texas A\&M University in 2000. In 2001, he joined the Center for Neurologic Diseases at Harvard Medical School, first as a research fellow and then as an instructor of neurology. In 2005, he joined the Brain Mind Institute at the Swiss Federal Institute of Lausanne as an assistant professor. His research interests are focused on protein fibrillogenesis and its role in neurodegenerative diseases. 
crucial for the advancement of our fundamental understanding of amyloid-related diseases as well as for the development of much needed prevention and therapeutic strategies.

\section{Protein Misfolding and Fibril Formation at Membrane Surfaces}

Numerous studies have demonstrated that lipid membranes can accelerate or even catalyze the conversion of amyloidogenic proteins into misfolded toxic aggregates. ${ }^{[9]}$ As amyloid proteins and lipids share an amphipathic structure, the association of amyloid proteins with membrane surfaces is conceptually a natural scenario. For cationic proteins, such as $\mathrm{A} \beta$ and IAPP, and the membrane-binding N-terminal region of $\alpha$-synuclein, ${ }^{[14]}$ the initial binding event is driven largely by electrostatic interactions between basic side chains and anionic lipid headgroups. ${ }^{[10 \mathrm{~b}]}$ Further hydrophobic contacts with the buried acyl chains, as well as the subsequent accumulation of protein on the membrane surface, increases the local protein concentration and facilitates the aggregation process. ${ }^{[10 b]}$ Therefore, depending on the composition of the membrane and its chemical properties, membranes are capable of providing a template for the misfolding and ordering of amyloidogenic proteins into fibrils. ${ }^{[10 a]}$ In this section, we review the most recent investigations with membrane model systems into the role of lipid membranes in templating the formation of toxic aggregates and amyloid fibrils. ${ }^{[9]}$

\subsection{Nucleation Polymerization Pathway for Fibrillogenesis and Possible Mechanisms for Membrane-Assisted Aggregation}

In the absence of catalysis, amyloid proteins follow a nucleation polymerization pathway that is characterized by an initial lag phase dominated by monomeric constituents, followed by an unfavorable conformational shift to a $\beta$ sheet and the assembly of monomers into oligomeric "nuclei", which then assemble into higher-order protofibrils (Figure 1). ${ }^{[15]}$ The nucleus cooperatively and rapidly elongates through monomer addition into the growing protein polymer according to a sigmoidal kinetic curve (Figure 1). ${ }^{[16]}$ In vitro, the nucleation of $A \beta$ occurs above its critical micelle concentration (CMC), which is in the range of $17.5-100 \mu \mathrm{M}$, depending on the length of the peptide. ${ }^{[17]}$ In fact, the physiological concentration of $\mathrm{A} \beta$ is orders of magnitude below this level. It has been measured in the subnanomolar range in cerebral spinal fluid. ${ }^{[18]}$ This finding suggests that $A \beta$ fibrillogenesis, as well as that of other amyloidogenic proteins, follows an alternative mechanism in vivo: possibly a templateassisted mechanism in which components in the local environment lower the free-energy barrier to nucleation. Data from model systems point to the cell membrane as a likely catalyst of fibril formation, ${ }^{[10,19]}$ whereby the binding of proteins to the membrane surface serves as a platform for nucleation and further polymerization. ${ }^{[10 b]}$

There are several possible mechanisms by which membrane-surface binding can facilitate protein misfolding and

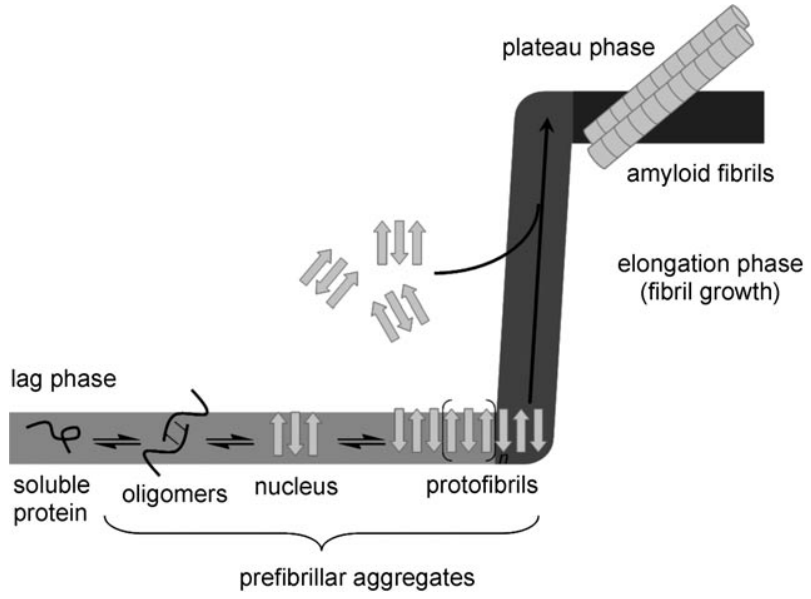

Figure 1. Depiction of the nucleation polymerization pathway for amyloid fibrillogenesis (adapted from reference [20])

aggregation. Adsorption of the unfolded amphipathic peptide to the membrane surface could reduce the conformational entropy of the peptide and impart structural ordering, thereby inducing the formation of secondary structure. ${ }^{[21]}$ The ability of membranes to induce regions of locally concentrated proteins has also been referred to as "molecular crowding". ${ }^{22]}$ Bokvist and Gröbner recently demonstrated the influence of molecular crowding on $\mathrm{A} \beta$ conformational shifts in the presence of model membrane surfaces. Ficoll 70, a large, neutral crowding polymer, was able to promote the conformational transition of vesicle-bound $A \beta$ to a $\beta$-sheet structure. $^{[23]}$

In addition to increasing the local protein concentrations, other factors have been proposed to play a role in membranemediated fibrillogenesis. Lowering of the local solvent dielectric constant by the microenvironment of the membrane surface may facilitate the formation of peptide-peptide hydrogen bonds in the $\beta$-sheet aggregate. ${ }^{[24]}$ The reduction of the dimensionality from three dimensions in solution to approximately two dimensions on the membrane interface can also introduce spatial restrictions that favor the fibrilformation pathway. ${ }^{[22]}$

\subsection{Membrane-Binding Regions of AB, IAPP, and $\alpha$-Synuclein and the Role of $\alpha$-Helical Intermediates}

In many cases, membrane-mediated protein misfolding and fibril formation proceeds via transiently populated $\alpha$ helical intermediates (Scheme 1). ${ }^{[25]}$ Depending on the relative peptide-to-lipid concentration, ${ }^{[11 b]} \mathrm{A} \beta,{ }^{[26]}$ IAPP,${ }^{[27]}$ and $\alpha$ synuclein $^{[28]}$ have all been shown to shift to an $\alpha$-helical structure upon membrane binding. This transformation would appear to be a counterproductive pathway in terms of fibril formation. ${ }^{[21]}$ Even in an $\alpha$-helical state, however, the anchoring of the aggregation-prone peptides to the membrane surface will enhance the local protein concentration in the immediate microenvironment and thus favor conformational switching to a $\beta$-sheet structure and protein aggregation. ${ }^{[10 b, 25]}$ Conformational shifting from a random coil free in 
solution to a membrane-bound $\alpha$ helix and then to a $\beta$-sheet aggregate upon sample aging has been reported for $A \beta^{[26 a]}$ and IAPP; ${ }^{[27 b, 29]}$ thus, this transformation seems to be an underlying mechanism in membrane-mediated fibrillogenesis. The existence of $\alpha$-helical states prior to $\beta$-sheet formation has also been detected during fibril formation of nonmembrane-bound $A \beta$ and IAPP in solution. ${ }^{[25,27 a, 30]}$ Herein, we outline what is currently known concerning the structures of the membrane-bound $\alpha$ helices for A $\beta$, IAPP, and $\alpha$ synuclein, as well as the key regions involved in the mediation of their interactions with membranes.

\subsection{1. $\boldsymbol{A} \boldsymbol{\beta}$}

The A $\beta$ peptide is a $39-42$ residue peptide that is produced by sequential cleavage of the transmembrane amyloid precursor protein (APP) by $\beta$ - and $\gamma$-secretase (Figure 2). The peptide contains six negatively charged

Aß42:
DAEFRHDSGYEVHHQKLVFFAEDVGSNKGAIIGLM
VGGVVIA
hIAPP:
KCNTATCATQRLANFLVHSSNNFGAILSSTNVGSNTY
$\alpha$-synuclein:
MDVFMKGLSKAKEGVVAAA EKTKQGVAEAA
GKTKEGVLYG SKTKEGVVHGVATVAEKTKE
QVTNVG GAVVTGVTA VAQKTVEGAGSIAAAT
GFVKKDQLGKNEEGAPQEGILEDMPVDPDNE
AYEMPSEEGYDYEPEA

Figure 2. Sequences of $A \beta 42$, the human form of IAPP (hIAPP), and $\alpha$ synuclein. For A $\beta 42$ and hIAPP, residues that have been observed to bind to membranes with the induction of $\alpha$-helical structure are underlined. For $\alpha$-synuclein, the 11 -mer repeats involved in membrane binding are underlined, the NAC region is italicized, and the C-terminal acidic region is in bold.

residues, six positively charged residues, and a hydrophobic $\mathrm{C}$ terminus. Earlier model studies with micelles or membranemimicking solvents, such as trifluoroethanol (TFE) or hexafluoroisopropanol (HFIP), established that $\mathrm{A} \beta 40$ and $\mathrm{A} \beta 42$ adopt $\alpha$-helical structures in the presence of membrane mimics. However, the region of the protein which adopts helical structures is strongly dependent on experimental conditions. ${ }^{[26 b-d, 31]}$ Fletcher and Keire observed a helical structure in the region comprising residues 16-24 in fragment $\mathrm{A} \beta(12-28)$ in the presence of SDS micelles $(3 \mathrm{~mm}) \cdot{ }^{[26 \mathrm{~b}]}$ Other studies with SDS or dodecylphosphocholine (DPC) micelle models showed the presence of $\alpha$-helical structures in the central regions (12-36) flanked by unstructured $\mathrm{N}$ and $\mathrm{C}$ termini, ${ }^{[26 c, 31 a]}$ as well as helix-loop-helix regions in both $\mathrm{A} \beta 40$ and $\mathrm{A} \beta 42 .{ }^{[26 \mathrm{~d}]}$

\subsubsection{IAPP}

Human IAPP (hIAPP) is a 37 residue peptide hormone with a disulfide bridge between residues Cys2 and Cys7 that constrains the first four residues in a disordered hairpin loop (Figure 2). ${ }^{[32]}$ The peptide has several cationic residues which mediate contacts with anionic membranes, and a hydrophobic C-terminal region (residues 30-37). Residues 23-29 form a highly amyloidogenic fragment which may be involved in initiating protein aggregation. ${ }^{[27 c]}$

Resolution of the $\alpha$-helical conformation of the SDSmicelle-bound peptide by NMR spectroscopy showed the presence of a core helix composed of residues 5-28 and a disordered $\mathrm{C}$ terminus. ${ }^{[32]}$ The truncated peptide hIAPP ${ }_{1-19}$ also binds to membranes with a simultaneous shift to a $\alpha$ helical structure, but does not fibrillate. ${ }^{[33]}$

By using paramagnetic colliders on site-directed spinlabeled IAPP derivates, Langen and co-workers were able to elucidate the structure of IAPP bound to anionic POPScontaining vesicles. ${ }^{[27 c]}$ Residues $9-22$ of membrane-bound IAPP formed an amphipathic $\alpha$ helix parallel to the membrane surface (Figure 3). The hydrophobic face of the helix

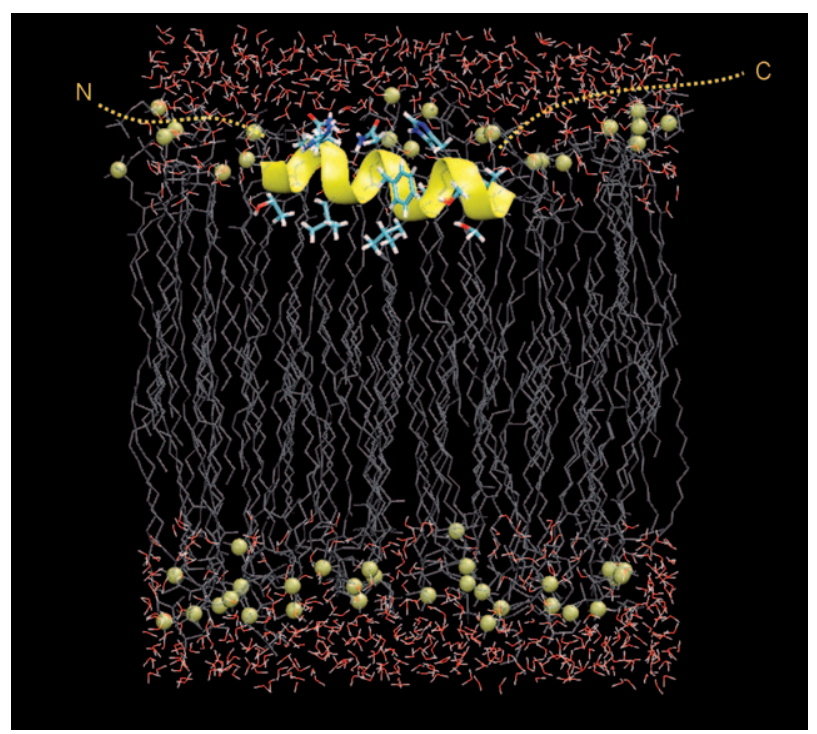

Figure 3. Membrane-bound structure of hIAPP derived from sitedirected spin labeling. ${ }^{[27 c]}$

was the least accessible to polar paramagnetic colliders, indicating the penetration of hydrophobic residues into the membrane and solvent exposure of the polar face of the helix. The helix was flanked by unfolded conformations, and the amyloidogenic residues 23-29 remained unstructured and exposed to the solvent. The authors proposed that surface accumulation of IAPP, as well as other factors, such as a lowered solvent dielectric constant at the membrane surface, facilitates the conformational transition of the peptide (initiated by the amyloidogenic fragment 23-29) into $\beta$ sheet aggregates. ${ }^{[27,28 a]}$ A membrane-bound $\alpha$-helical conformation of IAPP anchored to anionic POPG monolayers through interactions with the cationic $\mathrm{N}$-terminal region was also detected by infrared reflection absorption spectroscopy. ${ }^{[29]}$ Shifts in the membrane-bound IAPP from an initial $\alpha-$ helical conformation to $\beta$-sheet networks were observed by monitoring the characteristic wave numbers for $\alpha$ helices and $\beta$ sheets over a 15 hour period. ${ }^{[29]}$ 


\subsection{3. $\alpha$-Synuclein}

The sequence of $\alpha$-synuclein can be divided into three main regions: 1 ) the $\mathrm{N}$ terminus (residues $1-60$ ), which binds to membrane surfaces with a concomitant conformational shift to an $\alpha$-helical structure $\left.;^{[14,28 a, d, 34]} 2\right)$ the middle hydrophobic region, or non-amyloid component (NAC) region, which comprises residues 60-95 and displays a high tendency to aggregate into $\beta$-sheet-rich amyloid fibrils; and 3 ) the acidic C-terminal region (residues 95-140), which is highly negatively charged and unstructured (Figure 2). ${ }^{[35]}$

The N-terminal membrane-binding region contains seven amphiphilic Lys-Thr-rich 11-residue imperfect repeats, which extend into the NAC region, and which have been referred to as the membrane-binding "hot spots" of the protein (Figure 2) ${ }^{[14]}$ A combination of NMR spectroscopy and molecular dynamics (MD) simulations have suggested that the $\mathrm{N}$-terminal residues adopt a slightly underwound $\alpha-11 / 3$ helix (11 residues per 3 complete turns), as opposed to the canonical $\alpha-18 / 5$ helix, to optimize the amphiphilicity of the membrane-bound helix. ${ }^{[36]}$ In MD simulations, the hydrophobic face of the $\alpha-11 / 3$ helix contacts the membrane, the anionic face is directed toward the solvent, and the Lys-Thr repeats lie at the polar/nonpolar interface of the membrane. Deletion of the N-terminal residues led to the attenuation of $\alpha$-synuclein toxicity toward yeast, indicating the toxicity of $\alpha$ synuclein is correlated with its binding to membranes through N-terminal residues. ${ }^{[35,37]}$

Depending on the surface curvature of the model membrane, membrane-bound $\alpha$-synuclein can adopt an extended $\alpha$-helix, ${ }^{[28 \mathrm{~d}]}$ a bent $\alpha$-helix, ${ }^{[28 \mathrm{a}]}$ or an antiparallel helix-turn-helix conformation. ${ }^{[28 b, c, 34 b]} \alpha$-Synuclein bound to SDS micelles adopts an antiparallel helix-turn-helix conformation to accommodate the high surface curvature of the membrane (Figure 4a). ${ }^{[28 b]}$ Bent $\alpha$-helical structures for vesicle-bound $\alpha$-synuclein were determined by site-directed spin labeling (Figure 4b), ${ }^{[28 a]}$ and a fully extended $\alpha$ helix was demonstrated for $\alpha$-synuclein bound to large vesicles ${ }^{[34 c]}$ or bicelle model membranes which present a flattened membrane surface (Figure 4c) ${ }^{[28 \mathrm{~d}]}$ In all cases, however, the Cterminal region did not contact the membrane and remained unstructured. Extended $\alpha$-helical structures of membranebound $\alpha$-synuclein more likely represent the situation in vivo, in which membrane surfaces have relatively low curvature. Even aged samples of $\alpha$-synuclein, with an expected $\beta$-sheet oligomeric conformation, were shown to bind to vesicles with the induction of $\alpha$-helical structure. ${ }^{[38]}$ Direct evidence for a subsequent shift to $\beta$-sheet aggregates is lacking for $\alpha$ synuclein, and studies have demonstrated both the inhibition of fibril formation with $\mathrm{PG} / \mathrm{PC}$ vesicles ${ }^{[39]}$ and the enhancement of fibril formation with brain membranes. ${ }^{[40]}$ Although the acceleration of $\alpha$-synuclein-fibril formation in the presence of micelles was reported by Necula et al. ${ }^{[41]}$ the existence of helical intermediates was not demonstrated in this case. a)

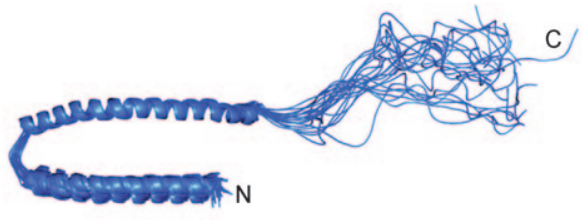

b)

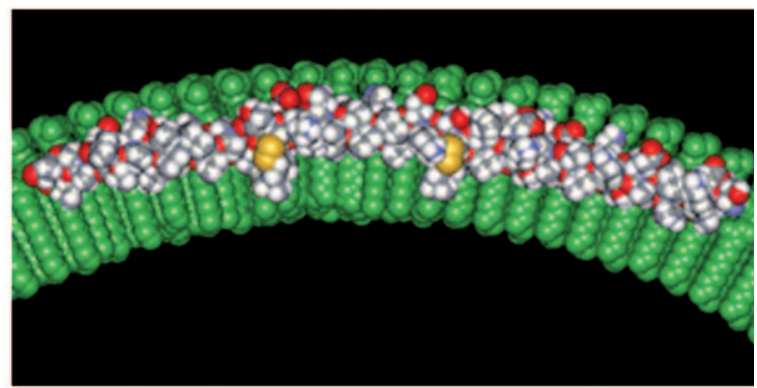

c)

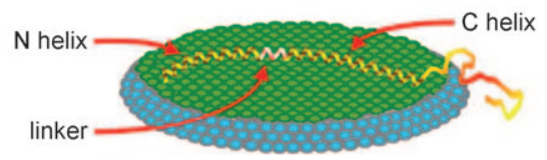

Figure 4. $\alpha$-Helical conformations of $\alpha$-synuclein bound to various model membranes. a) Superposition of 20 structures of $\alpha$-synuclein bound to SDS micelles (reproduced from reference [28b]). The structures, which were derived by NMR spectroscopy, show a frayed $C$ terminus. b) Bent $\alpha$ helix of vesicle-bound $\alpha$-synuclein, as derived from site-directed spin labeling (reproduced from reference [28a]). c) Extended $\alpha$-helical conformation of bicelle-bound $\alpha$-synuclein (reproduced from reference [28d]).

\subsection{Factors Influencing Membrane-Mediated Fibril Formation}

In this section, we examine recent results demonstrating the acceleration of fibril formation in amyloidogenic proteins in the presence of certain membrane compositions and under certain experimental conditions, with a focus on: 1) anionic lipids, 2) ganglioside clusters, cholesterol, and lipid rafts, 3 ) the influence of metal ions, and 4) the role of the peptideto-lipid ratio.

\subsubsection{Anionic Lipids}

The preference for $A \beta$ binding to membranes with anionic lipid headgroups is a recurring observation..$^{[10 a, 23,42]}$ By using $\mathrm{X}$-ray- and neutron-scattering techniques, Lee and co-workers demonstrated that $\mathrm{A} \beta 40$ inserts spontaneously into anionic DPPG rather than zwitterionic DPPC lipid monolayers. ${ }^{[10 a]}$ Only the DPPG monolayers were capable of inducing the crystalline ordering of $A \beta$ to give diffraction patterns reminiscent of $\beta$-sheet aggregates. ${ }^{[10 \mathrm{a}]}$ The interaction between A $\beta 40$ and DPPG was abolished, however, upon raising the $\mathrm{pH}$ value to $7.4, \mathrm{~A} \beta$ becomes anionic and repels the anionic lipid headgroups. The authors further confirmed the fibril-templating effect of PG headgroups by incubating A $\beta$ with POPC vesicles containing $30 \%$ POPG in water, which resulted in the acceleration of fibril formation. They proposed that the exposure of anionic lipids on the outer leaflet of cell membranes as a result of oxidative stress may be a trigger for fibrillogenesis in vivo. 
In an assay based on Förster resonance energy transfer (FRET) with tryptophan-labeled A $\beta 40$, Wong et al. observed a dramatic enhancement in $\mathrm{A} \beta 40$ binding to DPPC vesicles upon the incorporation of $30 \%$ anionic DPPG headgroups. ${ }^{[11 \mathrm{~b}]}$ Enhanced blue shifting of the tryptophan label in the presence of the anionic vesicles demonstrated peptide penetration into the anionic liposomes. ${ }^{[11 b]}$ PG-containing vesicles induced a $\beta$-sheet conformation in $A \beta 40$ as well as peptide oligomerization. ${ }^{[11 \mathrm{~b}]}$

The induction of fibril formation on anionic membranes has also been observed with $\operatorname{IAPP}^{[27 b, d]}$ and $\alpha$-synuclein. ${ }^{[34 a, 38,43]}$ The binding of IAPP to anionic membranes containing PS or PG was shown to dramatically enhance its fibril formation. ${ }^{[19,21,24,27 \mathrm{~d}]} \mathrm{X}$-ray reflectivity measurements demonstrated lipid-induced fibril nucleation of IAPP in the presence of anionic mixed DOPC/DOPG monolayers, but not with purely zwitterionic DOPC monolayers. ${ }^{[4]}$ Increases in anionic-headgroup content in mixed vesicles have been shown to promote the binding of $\alpha$-synuclein monomers ${ }^{[34 a, 45]}$ and oligomers. ${ }^{[46]}$ Furthermore, the propensity of $\alpha$-synuclein to cluster on the membrane surface has been shown to increase with increasing membrane anionic-lipid content. ${ }^{[43]}$ The promotion of $\alpha$-synuclein-fibril formation was also demonstrated in the presence of anionic micelles. ${ }^{[41]}$

\subsubsection{Ganglioside Clusters, Cholesterol, and Lipid Rafts}

In the outer membrane leaflet, ganglioside lipids cluster with sphingomyelin and cholesterol to form rigid microdomains known as lipid rafts, which are characterized by slow lateral diffusion of the lipid acyl chains as well as detergent resistance ${ }^{[47]}$ Ganglioside lipids are a class of glycolipids that contain an anionic sialic acid headgroup and are prevalent on neuronal cells. ${ }^{[4]}$ The ganglioside content, cholesterol content, and overall fluidity (ordered versus disordered) of membranes have all been shown to be important factors in the anchoring of amyloidogenic proteins to membranes and have been shown to influence their fibrillization rates. ${ }^{[49]}$

The enhanced binding of $\mathrm{A} \beta$ and acceleration of fibril formation with ganglioside-containing membranes has been reported on several occasions. ${ }^{[26 a, 42 a, 50]}$ In fact, ganglioside clusters have been proposed by Matsuzaki to form sites on the cell membrane that are designated for the sequestering of $A \beta$ after cleavage from the amyloid precursor protein (APP) and the seeding of its fibril formation (Figure 5). ${ }^{[42 \mathrm{a}]}$ In support of this hypothesis, correlations exist between the ganglioside content in the cell membrane and the occurrence of AD. ${ }^{[42 a, 51]}$ Ganglioside clusters have recently been targeted with com-

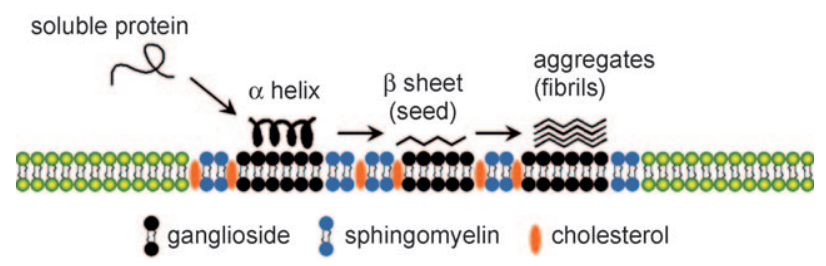

Figure 5. Templating of $A \beta$-fibril formation on ganglioside clusters in lipid rafts. pounds that bind to the membrane and inhibit $A \beta$ aggregation on its surface as well as the associated toxic effects of $A \beta$ on PC12 cells. ${ }^{[52]}$

The binding of $A \beta$ to ganglioside-containing membranes induces a random-coil-to- $\alpha$-helix transition at low peptide/ lipid ratios $(\leq 0.025)$, and at higher peptide/lipid ratios $(\geq 0.05)$ promotes the adoption of a $\beta$-sheet conformation, which then triggers fibril formation (Figure 5). ${ }^{[26]}$ The incubation of $A \beta 40$ with the monoganglioside GM1 in a 1:1 molar ratio induced $\beta$-sheet formation and aggregation in the peptide after 12 hours. ${ }^{[26]}$ Under the same conditions in the absence of GM1, A $\beta$ remained monomeric and unstructured. Interestingly, $A \beta 40$ fibrils formed in the presence of GM1 showed a higher cytotoxicity on PC12 cells than those formed without GM1 and exhibited distinct morphological features by TEM. ${ }^{[26 a]}$ This result suggests that gangliosides interact with $\mathrm{A} \beta$ to produce structurally unique fibrillar structures with enhanced cytotoxcity. The accelerated $\beta$-sheet formation and aggregation of $A \beta$ in the presence of raftlike liposomes containing GM1, cholesterol, and sphingomyelin has also been reported. ${ }^{[50]}$ The resulting $A \beta$ fibers demonstrated a unique structural morphology and increased cytotoxicity. ${ }^{[50]}$ The existence of GM1 in a raftlike membrane environment was proven to be essential for triggering $A \beta$-fibril formation, as no induction of $\beta$-sheet aggregates was observed with raftlike sphingomyelin/cholesterol liposomes in the absence of GM1, nor with mixed GM1/PC liposomes.

The accumulation of IAPP amyloid deposits on membranes containing ganglioside-rich domains has been demonstrated by fluorescence imaging. ${ }^{[53]}$ A direct correlation was observed between the amount of IAPP fibrils deposited on membranes and the membrane ganglioside content; this relationship suggests that a high ganglioside content stimulates IAPP-fibril formation in vivo. ${ }^{[53]}$ Prion proteins have also shown a clear preference for binding to GM1/cholesterol/ spingomyelin-containing vesicles as monomeric $\alpha$ helices, which suggests that lipid rafts also play a role in the anchoring of prion proteins to membranes. ${ }^{[54]}$

In contrast to the reported accumulation of A $\beta$, IAPP, and prion proteins on ordered lipid-raft domains, $\alpha$-synuclein showed a preference for localization on liquid-disordered phases in anionic vesicles. ${ }^{[45]}$ In a separate study, oligomeric preparations of $\alpha$-synuclein also showed a preference for binding to liquid-disordered regions, as determined by fluorescence microscopy. ${ }^{[46]}$ The greater packing density of anionic headgroups on the surface of liquid-ordered phases in lipid rafts was proposed to repel the negatively charged $\mathrm{C}$ terminus of $\alpha$-synuclein. ${ }^{[46]}$

Conflicting results have indicated that cholesterol can either inhibit ${ }^{[55]}$ or promote ${ }^{[56]} \mathrm{A} \beta 40$ penetration into model liposomes, depending on the molar ratio of cholesterol in the membrane. In neuroblastoma cells, cholesterol enrichment in lipid-raft domains has been shown to prevent the cell-surface association of $A \beta 42$ oligomers. ${ }^{[57]}$ These reports suggest that a specific mole fraction of cholesterol within lipid rafts is necessary for the promotion of $\mathrm{A} \beta$ surface binding. ${ }^{[56]}$ Furthermore, AFM images showed a marked decrease in the number and size of IAPP particles accumulated on the surface of PC:PS planar lipid bilayers upon the incorporation 
of cholesterol into the membranes, which suggests that the membrane cholesterol content also influences IAPP fibrillogenesis. $^{[58]}$

\subsubsection{Influence of Metal lons}

Elevated levels of metal ions have been reported in the substantia nigra of PD patients, ${ }^{[59]}$ and $\mathrm{Cu}^{2+}, \mathrm{Fe}^{3+}$, and $\mathrm{Zn}^{2+}$ ions are found concentrated in neuronal plaques of $\mathrm{AD}$ afflicted patients. ${ }^{[60]}$ It is therefore thought that metal ions may influence the aggregation and toxicity of amyloidogenic proteins. ${ }^{[61]}$ In vitro, certain metal ions influence the structure and fibrillization rates of amyloidogenic proteins. ${ }^{[62]}$ For example, the addition of metal cations, such as $\mathrm{Cu}^{2+}, \mathrm{Fe}^{3+}$, and $\mathrm{Co}^{3+}$, was shown to induce secondary structure in $\alpha$ synuclein and significantly accelerate fibril formation. ${ }^{[63]}$

In vitro studies have also indicated that metal ions can mediate the interaction between amyloid proteins and membranes. Interestingly, the addition of $\mathrm{Ca}^{2+}$ and other heavy-metal ions to monomeric $\alpha$-synuclein was shown to rapidly produce annular pore-shaped oligomeric $\alpha$-synuclein of varying diameters. ${ }^{[6,64]}$ However, the failure of C-terminally truncated versions of $\alpha$-synuclein to adopt annular structures indicates that metal-cation binding is mediated by interactions with the acidic $\mathrm{C}$ terminus. Annular oligomers have been proposed to be possible toxic species that target membranes $;^{[7,12 b, 65]}$ thus, elevated concentrations of metal cations may stimulate toxic interactions between $\alpha$-synuclein oligomers and membranes. Indeed, detergent-resistant oligomeric structures of $\alpha$-synuclein that exhibit membrane conducting activity were induced with $\mathrm{Fe}^{3+} \cdot{ }^{[66]}$ Furthermore, the clustering of $\alpha$-synuclein on the surface of anionic POPG/PC bilayers was facilitated in the presence of divalent metal cations. ${ }^{[43]}$ It is possible that metal cations facilitate the interaction of the anionic $\mathrm{C}$ terminus of $\alpha$-synuclein with anionic membranes through partial charge neutralization of the membrane or by forming coordination bridges.

Earlier studies showed that $\mathrm{Zn}^{2+}$ and $\mathrm{Cu}^{2+}$ ions induced $\mathrm{A} \beta 42$ insertion into POPC/POPS vesicles at $\mathrm{pH}$ 5.5-7.5 with a corresponding induction of $\alpha$-helical structure. ${ }^{[55]}$ In the absence of the metal cations, $A \beta 42$ was only able to penetrate the membrane below $\mathrm{pH} 5.5$, which indicates that an increase in $\mathrm{A} \beta 42$ positive charge either through lowering of the $\mathrm{pH}$ value or through metal-cation complexation enhances A $\beta 42$ binding to membranes. More recently, ${ }^{31} \mathrm{P}$ and ${ }^{2} \mathrm{H}$ NMR solid-state NMR spectroscopic studies demonstrated that $\mathrm{Cu}^{2+}$ ions alone disrupt model membranes and induce the formation of smaller vesicles. ${ }^{[67]} \mathrm{A} \beta 42$ added to the system protected the membranes from $\mathrm{Cu}^{2+}$ disruption, possibly by scavenging the cations through coordination. ${ }^{[67,68]} \mathrm{A} \beta 42-\mathrm{Cu}^{2+}$ complexes were able to associate with the surface of anionic phospholipid membranes, as demonstrated by ${ }^{31} \mathrm{P}$ NMR spectroscopy. ${ }^{[67 a]}$

\subsubsection{Influence of the Peptide-to-Lipid Ratio}

Conversion from a largely unfolded conformation into an $\alpha$ helix upon membrane binding is a feature shared by $\mathrm{A} \beta{ }^{[11 \mathrm{~b}, 50,69]} \mathrm{IAPP}^{[21,27 \mathrm{a}, \mathrm{b}]}$ and $\alpha$-synuclein ${ }^{[28 \mathrm{a}-\mathrm{c}, 34 \mathrm{c}, 38]}$ that sug- gests a common mechanism for membrane-mediated misfolding and aggregation in these and other amyloid-forming proteins. Following initial membrane binding, the misfolding of amyloid-forming proteins into $\beta$-sheet aggregates depends critically on the relative concentrations of peptide and lipid. ${ }^{[11 \mathrm{~b}, 27 \mathrm{~b}]}$ In studies reported by Wong et al., the addition of increasing amounts of POPC/PG or DPPC/PG vesicles was shown to shift the conformation of membrane-bound $A \beta 40$ from a $\beta$-sheet to an $\alpha$-helical structure. This result led to a compelling mechanistic model relating the relative peptideto-lipid concentration to the membrane-bound structure of the protein: $:^{[11 b]}$ At low peptide-to-lipid ratios (high lipid content), the adsorption of amyloid proteins to the membrane surface effectively shields protein-protein interactions and impedes fibrillogenesis. In this case, the $\alpha$-helical conformation of the membrane-bound protein dominates (Figure 6).

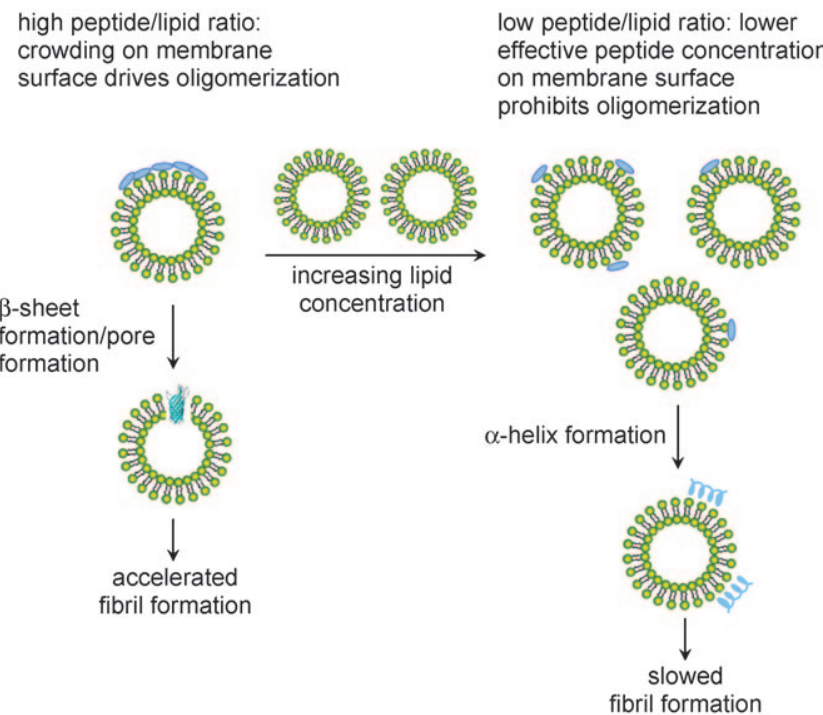

Figure 6. Influence of the peptide/lipid molar ratio on fibril-formation rates, as proposed by Wong et al. ${ }^{[11 \mathrm{~b}]}$

When the relative peptide concentration is increased to a critical peptide-to-lipid ratio, crowding of the protein on the membrane surface stimulates protein-protein interactions, a shift to a $\beta$-sheet structure, and fibril growth (Figure 6). Thus, depending on the peptide-to-lipid ratio, membranes can either inhibit fibrillogenesis at high relative lipid concentrations, or accelerate fibrillogeneis at lower or intermediate concentrations. This mechanistic phenomenon has been observed with both $A \beta^{[10 a, 11 b, 26 c, 50]}$ and IAPP ${ }^{[21]}$ in contact with anionic membranes and parallels previously reported mechanistic aspects of antimicrobial peptide-membrane interactions. ${ }^{[70,71]}$ As an example, at a constant peptide concentration, $\mathrm{A} \beta$ is $\alpha$-helical in the presence of DPC micelles at a concentration of $20 \mathrm{~mm}$ and is a $\beta$ sheet in the presence of DPC micelles at a concentration of $5.5 \mathrm{~mm}^{[26 \mathrm{c}]}$ 


\subsection{Reversing Amyloid-Fibril Formation with Lipids}

Remarkably, Rousseau and co-workers reported that DOPC liposomes disassemble mature and inert A $\beta 42$ amyloid fibrils into soluble toxic protofibrillar species, thereby inducing the reverse process of fibrillogeneisis. ${ }^{[72]}$ The biophysical and toxicity characterization of the protofibrils obtained from the reverse reaction showed that they were identical to protofibrils obtained by the ageing of monomeric A $\beta 42$. Widenbrant et al. corroborated this finding by demonstrating the fragmentation of $A \beta$ fibrils into smaller nanoassemblies in the presence of DOPA membranes. ${ }^{[73]}$ These results are in contradiction with the numerous reports describing the acceleration of fibril formation on membrane surfaces, rare examples of an attempt to monitor the influence of lipids on the reverse process of fibril formation by using developed fibrils as a starting point. Additional studies are required to further validate this effect and to understand its biological effect, possibly in fibril clearance.

\section{Mechanisms of Amyloid-Mediated Membrane Permeabilization}

Increasing evidence indicates that the toxicity of amyloidforming proteins is directly correlated with their shared ability to disrupt the membrane barrier function. The initial discovery by Arispe and co-workers that $\mathrm{A} \beta$ exhibits ionchannel activity in planar lipid bilayers led to early proposals that the toxicity of $A \beta$ is based on an ion-channel mechanism that causes membrane depolarization, $\mathrm{Ca}^{2+}$ leakage, and a disruption of ionic homeostasis. ${ }^{[8,12 \mathrm{e}-\mathrm{g}, 74]}$ Channel activity was later reported for a number of other amyloidogenic proteins, including IAPP,${ }^{[74 c]} \alpha$-synuclein, ${ }^{[11 a, 65,75]}$ polyglutamine,${ }^{[76]}$ and prion-derived peptides. ${ }^{[7]}$ Thus, the toxicity of these proteins may be related to their shared capabilities to form channels or pores in membranes and to enable unregulated ion leakage in analogy to the mode of action of the pore-forming toxins (Scheme 1). ${ }^{[7 \mathrm{~b}, 12 \mathrm{a}, \mathrm{e}]}$ This conclusion is consistent with the fact that a disruption of $\mathrm{Ca}^{2+}$-ion homeostasis is a characteristic feature of several neurodegenerative diseases, including AD and $P D .^{[78]}$ The direct visualization of annular, or ringlike, structures of oligomeric protofibrils of several amyloidogenic proteins by electron and atomic force microscopy added additional fuel to the increasingly accepted amyloid-pore hypothesis. ${ }^{[7,8,12 \mathrm{~b}, \mathrm{c}, 79]}$

Although the disruptive influence of amyloidogenic proteins on membranes has become clear, the exact mechanisms by which these proteins induce membrane permeabilization are not yet fully understood. The amyloid-pore hypothesis is one proposed mechanism, but other possibilities have been supported by experimental results. For example, several lines of experimental evidence argue against a pore model and indicate that prefibrillar aggregates do not fully penetrate the membrane, but rather associate with membrane surfaces, where they induce membrane thinning and leakage (Scheme 1). ${ }^{[4 a, b, 80]}$ Furthermore, even if a pore model is operative, it may not be a static structure, but rather an intermediate state which is followed by other processes, such as detergent-like membrane dissolution..$^{[13 b, c, 81]}$ Such transient pore structures characterize the mechanisms of many antimicrobial peptides and may relate to the activity of amyloidogenic proteins as well. ${ }^{[71,82]}$ Indeed, numerous chemical similarities between amyloidogenic proteins and antimicrobial peptides, such as an amphipathic structure, indicate that mechanistic insight can be derived from proposed models describing the permeabilization mechanisms of antimicrobial peptides.

Besides the range of possible modes of action, the identification of the membrane-active oligomeric state further complicates the issue, as the process of fibril formation is associated with several intermediate aggregation states that could have varying membrane-permeabilizing activities. ${ }^{[83]}$ Furthermore, the mechanisms of action may vary according to protein type, membrane composition, and experimental conditions. To enable a full understanding of the molecular basis of the toxicity of amyloid-related diseases, these mechanistic considerations must be delineated. In this section, we provide an overview of the proposed models of membrane permeabilization by amyloid-forming proteins and recent experimental support for proposed mechanisms where relevant.

\subsection{Pore Formation versus Nonspecific Membrane Permeabilization}

A current controversy regarding the mechanism of membrane permeabilization by amyloid-forming proteins concerns their ability to form membrane channels or pores. Increasing experimental data, such as ion-channel conductance activity, support the feasibility of a porelike mechanism and the hypothesis that such a mechanism is responsible for the toxic properties associated with amyloid-forming proteins (Scheme 1). On the other hand, significant experimental data indicate that oligomeric forms of these proteins bind to the surface of the membrane and cause general membrane thinning and ion leakage (Scheme 1). Recent experimental evidence in support of both models is presented in this section, including pivotal older reports.

\subsubsection{Evidence for Pore Formation}

Experimental observations consistent with a pore model include: 1) the induction of single-ion-channel currents characteristic of ion-channel or pore-forming proteins by a diverse variety of amyloidogenic proteins in model membranes, ${ }^{[7 b, 8 a, 12 e, 65,77 a]}$ 2) the enhanced membrane-permeabilization activity of amyloid oligomers relative to that of soluble monomers and mature fibrils, ${ }^{[4 a, 11 a, 38,65,75,84]} 3$ ) the blocking of the channel activity of amyloid oligomers by aggregation inhibitors, such as (-)-epigallocatechin gallate $\left.{ }^{[65,85]} 4\right)$ a size dependence with respect to dye leakage from model vesicle membranes that indicates the formation of pores of a defined diameter, ${ }^{[11 a, 75,86]} 5$ ) high-resolution images of annular porelike oligomeric structures of several amyloidogenic proteins, both in the presence and in the absence of membranes, ${ }^{[7,8,12 \mathrm{~b}]}$ and 6) the binding of the anti-amyloid-oligomer antibody A11 
to amyloid oligomers as well as to oligomers of pore-forming toxins, such as $\alpha$-hemolysin, with a resulting suppression of membrane-permeabilizing activity. ${ }^{[4 a, 87]}$ The details of these observations are highlighted in the following paragraphs.

The ability of a range of amyloid-forming proteins, such as $\mathrm{A} \beta,{ }^{[12 \mathrm{f}, \mathrm{g}, 88]} \alpha$-synuclein, ${ }^{[7 \mathrm{~b}, 65,89]}$ IAPP, ${ }^{[74 \mathrm{c}]}$ polyglutamine, ${ }^{[76]}$ serum amyloid $\mathrm{A},{ }^{[7 \mathrm{~b}]}$ and the prion proteins, ${ }^{[12 \mathrm{e}, 77,90]}$ to induce ion-channel currents with defined conductance states in planar lipid bilayers provides solid evidence that these proteins display channel or pore activity in membranes. ${ }^{[\mathrm{bb}]}$ In many cases, these amyloid-forming proteins display voltage dependency as well as cation selectivity, ${ }^{[12 \mathrm{e}]}$ which are characteristic features of true membrane ion channels and pores. ${ }^{[91]}$ In the case of $A \beta$, experimental conditions that promote peptide aggregation, such as an acidic environment, enhance the observed channel activity, whereas the addition of agents that block aggregation, such as Congo red, attenuates the channel activity. ${ }^{[12 e, 74 d]}$ These effects indicate that $A \beta$ channel structures are oligomeric. The observed blocking of $A \beta$ channel activity by external agents, such as Tris (Tris = tri(hydroxymethyl)amiomethane), $\quad \mathrm{Al}^{3+},{ }^{[12 \mathrm{f}]}$ $\mathrm{Zn}^{2+},{ }^{[74 b]}$ and other designed molecules, ${ }^{[92]}$ suggests opportunities for therapeutic intervention in pore activity. In many of these earlier experiments on ion-channel activity, however, monomeric preparations or reconstituted proteins with illdefined heterogeneous oligomeric states were used.

The addition of defined oligomeric preparations of $\alpha$ synuclein was recently shown to induce ion-channel activity in PC monolayers (Figure 7a). ${ }^{[65]}$ Ion-channel-like conductivity was specific for the oligomeric preparation, and was not observed with monomer and fibril preparations of $\alpha$-synuclein. ${ }^{[65]}$ Channel activity induced by oligomeric $\alpha$-synuclein in this system was blocked effectively with the green-tea polyphenol (-)-epigallocatechin gallate. ${ }^{[65]}$ Recent results have also shown that membrane permeabilization with oligomeric preparations of $\mathrm{A} \beta$ is blocked effectively with disaccharides and trimethylamine $N$-oxide: compounds that also attenuate $A \beta$ aggregation. ${ }^{[85]}$

Vesicle-permeabilization assays with prefibrillar aggregates of $\alpha$-synuclein, ${ }^{[75]}$ IAPP,${ }^{[84 a, 86]}$ and $\mathrm{A} \beta^{[85]}$ further suggest that membrane permeabilization by these proteins results from oligomeric pore structures. Only oligomeric protofibrillar $\alpha$-synuclein (and not the monomeric and fibrillar forms) was shown to bind and permeabilize PG and PC vesicles. ${ }^{[11]}$ Furthermore, the disease-linked mutants of $\alpha$-synuclein, A30P and A53T, showed higher permeabilization activities than the wild type; thus, permeabilization activity appears to be directly correlated with the toxicity of $\alpha$-synuclein. ${ }^{[75]}$ Likewise, toxic oligomeric and non-amyloid yeast prion Ure $2 p$ fibrils resembling the native structure, but not the nontoxic amyloid fibrils of the protein, induced dye release from PS vesicles. ${ }^{[84 \mathrm{~b}]}$

A porelike mechanism for protofibrillar $\alpha$-synuclein was proposed on the basis of the size dependency of dye leakage from dye-loaded vesicles. Smaller components, such as $\mathrm{Ca}^{2+}$ and dopamine, exhibited much higher leakage rates than larger polymers, such as fluorescein isothiocyanate (FITC)dextran and cytochrome $c$, in the presence of the protein. ${ }^{[75]}$ Similarly, the leakage of $\mathrm{Ca}^{2+}$ from $\mathrm{PG}$ vesicles permeabilized a) $2 \mathrm{nS}$

$0.2 \mathrm{nA} 12 \mathrm{~s}$

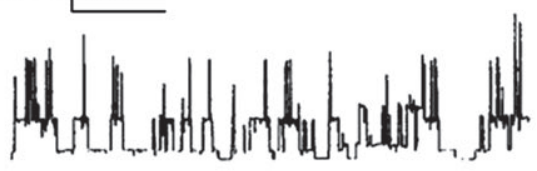

b)

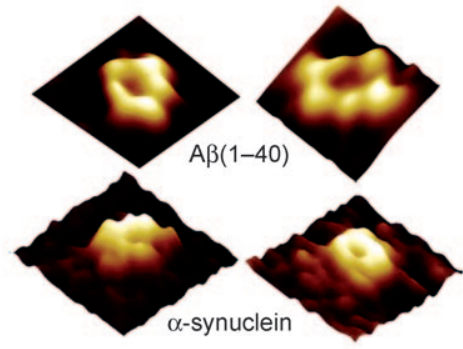

c)

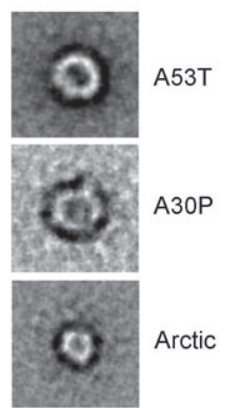

d)
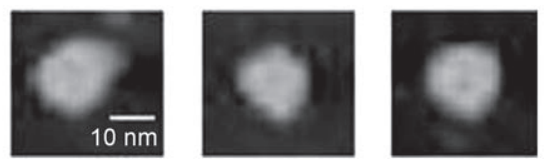

Figure 7. a) Ion-channel conductivity in planar lipid bilayers in the presence of oligomeric preparations of $\alpha$-synuclein (reproduced from reference [65]). b) AFM images of annular oligomeric structures observed for $A \beta(1-40)$ and $\alpha$-synuclein reconstituted in DOPC planar lipid layers (reproduced from reference [7b]). c) EM images of annular oligomeric structures observed for protofibrillar pathogenic mutants A53T and A30P of $\alpha$-synuclein and the A $\beta(1-40)$ "arctic" mutant (reproduced from reference [12b]). d) EM images of annular oligomeric structures observed for $\alpha$-synuclein pores released by the treatment of inclusions from multiple-system-atrophy post-mortem brain samples with a detergent (reproduced from reference [94]).

by protofibrillar IAPP was much faster than that of FITCdextran, a result that also advocates leakage through defined pores of limited diameter. ${ }^{[86]}$

The visual observation by AFM imaging of oligomeric channel structures of amyloidogenic proteins reconstituted in lipid bilayers is among the strongest experimental evidence in support of a pore mechanism. ${ }^{[7 b, 8 a]}$ AFM images of tetrameric to hexameric oligomers of $A \beta(1-42)$ reconstituted in DOPC lipid bilayers were initially obtained by Lal and co-workers. ${ }^{[8 a]}$ In 2005, the same group reported similar oligomeric channels formed by a range of amyloid-forming proteins reconstituted in DOPC bilayers, including $\alpha$-synuclein, IAPP, A $\beta(1-40)$, and serum amyloid $A$. Their results indicated that pore activity is a common feature that underlies the toxic behavior of amyloid-forming proteins. ${ }^{[7 b]}$ In approximately $15 \%$ of the images, the reconstituted proteins had formed multimeric supramolecular complexes composed of four to eight subunits with outer diameters of 8-10 $\mathrm{nm}$ and inner pore diameters of 1-2 nm (Figure 7b). ${ }^{[7 b]}$ Lansbury and co-workers demonstrated that isolated protofibrils of mutant amyloid-forming proteins that are associated with familial $\mathrm{AD}$ and $\mathrm{PD}$, including the $\mathrm{A} \beta(1-40)$ "arctic" mutant $\alpha$-synA30P and $\alpha$ synA53T, as well as wild-type $\alpha$-synuclein, also form annular pore structures in the absence of a lipid bilayer. ${ }^{[12 b, c]}$ The pore dimensions correlated well with those reported by Lal and co- 
workers. ${ }^{[7 b]}$ Namely, outer pore diameters were in the range of $7-10 \mathrm{~nm}$, and inner diameters were in the range of $1.5-2 \mathrm{~nm}$ (Figure $7 \mathrm{c}$ ). AFM images have also shown poration induced by the amyloidogenic prion-protein fragment PrP106-126 in supported lipid bilayers; however, the inner pore diameters were not reported in this case. ${ }^{[93]}$

Annular structures have also been isolated from postmortem samples. Their striking morphological resemblance to pore structures observed in vitro with recombinant and synthetic amyloid proteins suggests that these structures are obligate intermediates that occur in vivo. Even larger annular particles composed of $\alpha$-synuclein oligomers with diameters in the range of $30-50 \mathrm{~nm}$ were obtained by the treatment with detergent of cytoplasmic inclusions in post-mortem multiplesystem-atrophy brain tissue (Figure $7 \mathrm{~d}$ ) $\cdot{ }^{[6,94]}$ Inoue reported the observation of pore structures of $A \beta$ in neuronal cell membranes and mitochondria-like organelles from the brain tissue of AD patients by TEM. These pores were also larger than those observed in vitro, with outer diameters of $16 \mathrm{~nm}$ and pore openings of $10 \mathrm{~nm} .{ }^{[95]}$ The surprising similarity of the morphological features of oligomeric amyloid-forming proteins both in the presence and in the absence of a membrane, and of those extracted from in vivo samples, was naturally taken as a strong indication that these conformations either insert directly into membranes or form on the membrane (Scheme 1). Since it is accepted that amyloid-forming polypeptides of arbitrary sequence tend to aggregate into higherorder insoluble fibers with common morphological and structural features, it is also reasonable to consider that they share a similar tendency to form related intermediate structures: oligomeric pores that target cell membranes.

Recent studies have demonstrated that generic oligomeric pore structures, which may define the cytotoxic conformations of amyloid-forming proteins, are also adopted by other pore-forming toxins (PFTs) and pore-forming proteins (PFPs). Several striking structural and functional features that are shared by the amyloid-forming proteins and PFTs, including $\alpha$-hemolysin and anthrax toxin, implicating a similar mechanism for membrane permeabilization. ${ }^{[7 a, 87]}$ The ringshaped configurations observed by AFM and electron microscopy (EM) for the amyloid-forming proteins mirror those observed for PFPs, such as perforin and perfringolysin O. ${ }^{[87,96]}$ Furthermore, both pore-forming and amyloidforming proteins are synthesized as soluble proteins that are later converted into circular, toxic, oligomeric, and often $\beta$ sheet-rich transmembrane pores. ${ }^{[96]}$ In both classes of proteins, the process of oligomerization, which promotes channel formation, is accelerated by lipid rafts, which act as concentration platforms (Figure 5). ${ }^{[97]}$ Importantly, the conformation-specific anti-amyloid-oligomer antibody A11, which binds to amyloid oligomers regardless of their primary sequence, also reacts with oligomers, but not monomers, of $\alpha$-hemolysin and human perforin. ${ }^{[87]}$ Furthermore, binding to A11, which is known to inhibit the toxicity and membranepermeabilizing activity of amyloid oligomers, was also shown to suppress the hemolytic activity of $\alpha$-hemolysin oligomers. ${ }^{[87]}$

These common features together almost inarguably support the hypothesis that amyloid oligomers induce membrane permeabilization through an active structure and mechanism that correspond to those adopted by the PFTs and PFPs. Therefore, mechanistic questions regarding the activity of amyloidogenic proteins on membranes can be addressed by using biophysical techniques and mechanistic assays that have been instrumental in the elucidation of the mode of action of PFPs as well as related antimicrobial peptides on model membranes (see Section 4).

\subsubsection{Three-Dimensional Models of Oligomeric Pores}

Although the visual observation of the topological features of oligomeric pores has provocative implications regarding the mechanisms of membrane permeabilization by amyloid-forming proteins, three-dimensional atomic-level stuctures of amyloid pores have not yet been determined experimentally. Research in this area is hindered by the inherent insolubility and noncrystallinity of amyloid proteins, factors that are further exacerbated in membrane environments. Futhermore, well-defined oligomeric structures of amyloid-forming proteins are inherently transient and difficult to isolate and characterize. ${ }^{[65]}$ Three-dimensional pore models have been constructed computationally, and have contributed insight into possible conformational arrangements. By the computational parallel alignment of the NMRdetermined $\beta$-strand-turn- $\beta$-strand motif into annular disclike structures of $A \beta_{17-42}$, Nussinov and co-workers built a model for the $A \beta$ pore with dimensions that are in remarkable agreement with those determined by AFM and EM (Figure 8). ${ }^{[98]}$ Upon the insertion of these discs constructed from $\mathrm{A} \beta_{17-42}$ into an explicit DOPC bilayer, with the hydrophobic C-terminal strand interfacing the bilayer, moleculardynamics simulations demonstrated relaxation of the pore structures into subunits reminiscent of those observed by AFM (Figures $7 \mathrm{~b}$ and $8 \mathrm{a}$ ). ${ }^{[98]}$ Although the internal pore dimensions were a bit larger than in the experimental images (ca. $2.2-2.5 \mathrm{~nm}$ ), the outer diameters were in excellent agreement, and the height perfectly matched the thickness of a DOPC bilayer; these models therefore appear to be reasonable three-dimensional depictions. ${ }^{[98]}$ In this model it is assumed that the $\mathrm{N}$ terminus of $\mathrm{A} \beta$ does not participate in the channel structure but rather extends from the membrane. Other models of the $A \beta$ channel suggest tubular arrangements composed of subunits of cylindrically wound monomeric $A \beta$ that stack linearly to span the width of the bilayer. ${ }^{[99]}$ This model also predicts a water-filled channel of $1.5 \mathrm{~nm}$ in diameter.

Molecular modeling of the micelle-derived helical structure of $\alpha$-synuclein demonstrated head-to-head alignment of $\alpha$-synuclein dimer subunits, which arrange into ringlike hexamers and pentamers that superimpose with a pore structure determined by EM by Lashuel and co-workers (Figure $8 \mathrm{~b}){ }^{[12 b, c, 100]}$

\subsubsection{Evidence for Nonspecific Membrane Permeabilization}

Despite numerous reports of ion-channel activity involving defined open and closed conductance states, ${ }^{[7 b, 12 e, 101]}$ which are characteristic features of ion channels and pore toxins, ${ }^{[91]}$ 
a)

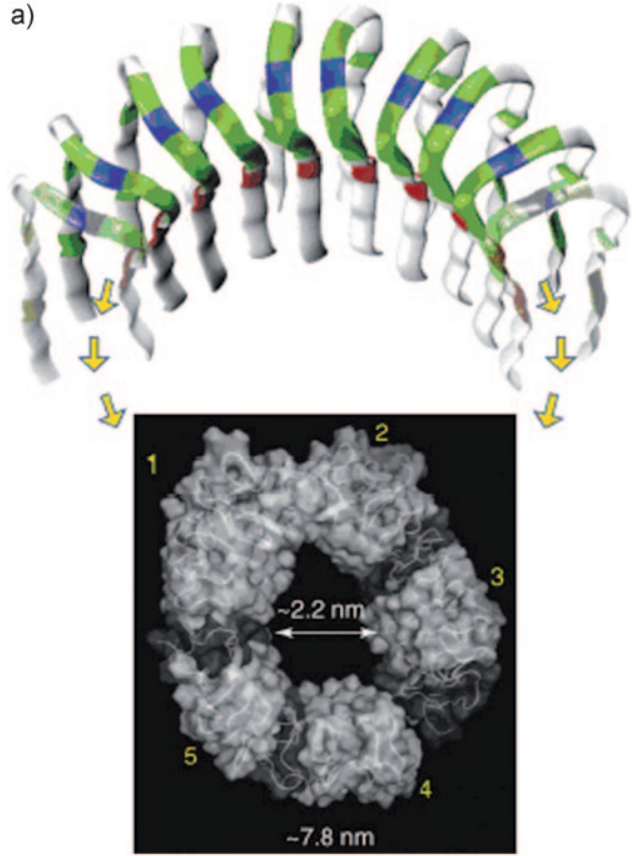

b)

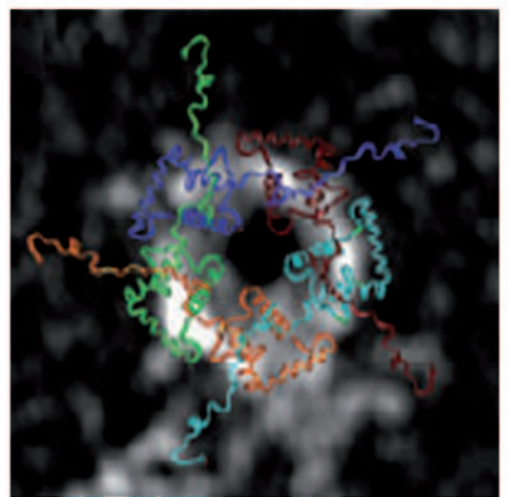

Figure 8. Computational models of: a) the $A \beta$ oligomeric pore (reproduced from reference [98]) and b) the $\alpha$-synuclein oligomeric channel superimposed with the pore structure determined by Lashuel et al. ${ }^{[12 b]}$ (reproduced from reference [100]).

as well as well-resolved pore structures for amyloid oligomers (Figure 7), evidence for ion-channel activity has not been reproduced by all research groups. ${ }^{[80 \mathrm{a}]}$ Seminal work by Glabe and co-workers demonstrated that preformed soluble oligomers, but not monomers or mature fibrils, of A $\beta$, IAPP, polyglutamine, and prion 106-126 clearly increased the general conductivity of model bilayers without the occurrence of the discrete conductance changes or open and closed states that characterize ion-channel activity. ${ }^{[4 a]}$ Although this finding does clearly support the hypothesis that oligomeric forms of amyloid-forming proteins are the membrane-permeabilizing species, it argues against the involvement of amyloid channels. More recently, Sokolov et al. showed that purified preparations of $\mathrm{A} \beta$ oligomers, which stained positive with antioligomer antibodies, also caused a general increase in model bilayer conductivity in a concentration-dependent manner when added externally to the bilayer, without single-channel current jumps supportive of ion-channel formation. ${ }^{[4 b]}$ These studies support a model in which amyloid oligomers bind to the membrane surface and disrupt lipid packing to cause membrane thinning and an increase in membrane leakiness without the formation of defined pores (Scheme 1). ${ }^{[4 \mathrm{~b}]}$

\subsubsection{Resolving the Issue with HFIP: The Pore Model Prevails}

The cause of the discrepancy concerning the ion-channel activity of amyloid-forming proteins has been a matter of debate for some time. Ion-channel activity was observed in cases in which proteins were fused to the membrane to generate proteoliposomes. In cases in which a general increase in membrane conductivity was observed, preformed preparations of the oligomeric proteins were added externally to the bilayer. ${ }^{[4 a, b, 80 b]}$ One explanation that has been put forward is that the formation of proteoliposomes by sonication enhances channel formation, whereas the membrane insertion of preformed oligomers added externally to the membrane may be hindered, so that only surface binding occurs. ${ }^{[80 a]}$ However, a recent study demonstrated that the lack of discrete ion-channel conductance patterns is an artifact of membrane permeabilization by residual hexafluoroisopropanol (HFIP), which was used in the preparation of preformed oligomers and masks the true ion-channel activity of amyloid-forming proteins. ${ }^{[12 \mathrm{~d}]}$ Capone et al. reported that samples of HFIP both with and without $A \beta$ showed identical current traces with a lack of defined conductance states and therefore concluded that the observed current was induced by HFIP alone. Remarkably, they showed that when HFIP was removed efficiently from oligomeric samples of $A \beta$ by purging with nitrogen, the stepwise ion flux across planar lipid bilayers that is characteristic of ion-channel activity was fully restored. ${ }^{[12 \mathrm{~d}]}$ A pore model is thus an experimentally valid and probable mechanism by which these oligomeric proteins target membrane integrity and induce cellular toxicity.

\subsection{Which Oligomeric Forms Are Responsible for Membrane Disruption?}

As described in the preceding paragraphs, oligomeric and protofibrillar forms of amyloid-forming proteins display higher membrane-permeabilization activities in model studies than the corresponding fibrillar or low-molecular-weight forms and are therefore thought to be the primary toxic species. ${ }^{[4 a, 11 a, 75,86]}$ However, the varying degrees of membranepermeabilizing activity of the range of oligomeric species along the spectrum from monomer to developed fibrils are poorly understood.

The number of oligomeric states that are possible for amyloid-forming proteins, ranging from dimers to fully developed fibrils with sizes on the order of $10^{6} \mathrm{Da}$, as well as the varying morphologies of intermediate aggregates, ${ }^{[83]}$ makes the identification of a membrane-active species with a defined oligomeric state and conformation a daunting task to say the least. Although little is known concerning the highresolution structural details of amyloid oligomers, a signifi- 
cant amount of research has been undertaken towards the classification of the structural types of amyloid oligomers on the basis of their varying immunoreactivities with conformation-specific antibodies. ${ }^{[83]}$ Prefibrillar oligomers (PFOs), which react with the A11 antioligomer antibody, are spherical particles with diameters in the range of 3-10 nm and form early during incubation. With longer incubation times, or upon catalysis with a hydrophobic-hydrophilic interface, PFOs are converted into annular protofibrils (APFs), ${ }^{[102]}$ which are thought to be circularized forms of PFO subunits, and which adopt porelike morphologies under the electron microscope (Figure 7). ${ }^{[12 b]}$ APFs bind to $\alpha$ APF antibodies and stain weakly to A11 antibodies; they therefore appear to have a different morphological arrangement to that of PFOs. Heptameric pores of $\alpha$-hemolysin also bind to $\alpha \mathrm{APF}$, which suggests that APFs adopt a $\beta$-barrel conformation. Fibrillar oligomers are another class of oligomeric intermediates that do not bind to A11 antibodies but show positive binding to osteocalcin (OC) antibodies and are thus structurally distinct from PFOs. ${ }^{[83]}$ Since OC antibodies are also specific for developed fibrils, fibrillar oligomers are thought to be small pieces of fibrils or fibril seeds that nucleate fibril growth. ${ }^{\left[{ }^{[3]}\right.}$

The morphological similarity between APFs and PFTs might suggest that APFs are the oligomeric form of amyloidogenic proteins that is responsible for membrane permeabilization. Furthermore, familial mutations associated with inherited forms of Parkinson's disease and Alzheimer's disease lead to an increase the population of APFs; this relationship suggests that these oligomeric forms are the primary toxic species. ${ }^{[12 b]}$ Surprisingly, however, Glabe and co-workers reported that PFOs of $\mathrm{A} \beta 42$ and $\alpha$-synuclein displayed much greater membrane-permeabilizing activity than the corresponding APFs in planar lipid bilayers. ${ }^{[102]}$ However, model membranes were found to accelerate the conformational shifting of PFOs into APFs, as detected on the basis of A11 and $\alpha$ APF immunoreactivity. ${ }^{[102]}$ The authors proposed that PFOs bind to the membrane, and it is the assembly of APFs from PFOs on the membrane which is the key event associated with membrane permeabilization and the process that enables the APF to form a membraneembedded $\beta$-barrel pore. In contrast, preformed APFs in solution lack sufficient capacity for membrane insertion. The inability of preformed pores of $\alpha$-hemolysin to induce membrane penetration ${ }^{[103]}$ suggests an analogous mechanism.

\subsection{Mechanistic Insight from Antimicrobial Peptides}

The mechanisms that govern the membrane-permeabilizing activity of antimicrobial peptides extend beyond solely pore-based mechanisms and may also be relevant for the elucidation of the membrane-active structures of amyloidogenic proteins. ${ }^{[0,71]}$ In fact, antimicrobial peptides and amyloid-forming proteins share many characteristics; they may therefore operate on the membrane through similar mechanisms. For example, both classes of polypeptides have the capacity to adopt amphipathic structures with hydrophobic and cationic hydrophilic ends and display enhanced affinities for negatively charged membrane surfaces. ${ }^{[42 a, 70]}$ Further- more, the shift in $A \beta,^{[11 b, 26 b-d]} \operatorname{IAPP}{ }^{[27 c, 32,33]}$ and $\alpha$-synuclein $^{[28 a, d, 34 a, b]}$ from a random-coil structure to an $\alpha$ helix upon initial contact with membrane surfaces reflects the conformational shifts of antimicrobial peptides in the presence of membranes (Scheme 1). ${ }^{[71 b]}$ For both antimicrobial peptides and amyloidogenic proteins, a threshold peptide concentration on the membrane surface is required for induction of the oligomeric membrane-permeabilizing species (Scheme 1). ${ }^{[11 b, 71 b]}$ Notably, the membrane-bound oligomeric species of certain antimicrobial peptides, such as temporins B and $\mathrm{L}$, have even been shown to undergo further conversion into amyloid-type fibrils. ${ }^{[104]}$

Although the mode of action of antimicrobial peptides on membranes is also still under debate, and many mechanistic questions remain, significantly more experimental data is available for these systems. This information has led to the development of a set of classic activity models. In the following paragraphs, we outline these mechanistic models, which explain the mode of action of antimicrobial peptides, pore-forming toxins, and designed amphipathic permeabilizing peptides on membranes, as these models may shed some light on the membrane activity of amyloidogenic proteins. ${ }^{[11,81]}$ We also highlight recent findings that demonstrate the adherence of amyloidogenic proteins to certain aspects of these activity models.

As the accumulation of permeabilizing peptides on a membrane surface reaches a critical local threshold concentration, oligomeric species form to create a transmembrane pore for which two structural arrangements have been proposed. In a barrel-stave pore, the hydrophobic regions of the peptide oligomer contact the hydrophobic membrane interior, and the hydrophilic ends line a water-filled pore. In this type of pore, variations in conductivity arise from monomer exchange with the transmembrane oligomer (Figure 9a). ${ }^{[71 a]}$ Barrel-stave pores perturb the membrane architecture only minimally, but create localized holes through which molecules can "leak" into or out of the membrane. ${ }^{[97]}$ Alternatively, in a toroidal-pore structure, the hydrophilic ends of the peptides remain in contact with the lipid headgroups. In this way, membrane curvature is induced, and a pore lined with both lipid headgroups and peptides is created that enables the passage of molecules through the membrane (Figure 9a). The toroidal pore is considered a metastable structure and is proposed to collapse by one of two mechanisms. In the sinking-raft model, the pore breaks down to give a resealed bilayer, with transbilayer equilibration of the peptides on the inner and outer membrane leaflets (Figure 9b) ${ }^{[81]}$ Alternatively, in the carpet model, the membrane is disintegrated into peptide-lipid aggregates in a detergent-like process (Figure $9 \mathrm{~b}$ )..$^{[82]}$

Recent results indicate that IAPP, in particular, operates via toroidal-pore intermediates. Differential scanning calorimetry (DSC) and solid-state NMR spectroscopic experiments indicate that IAPP induces severe curvature strain on model membranes, which is indicative of toroidal-pore structures. ${ }^{[105]}$ The incorporation of membrane-disrupting IAPP fragments $\left(\mathrm{hIAPP}_{1-37}, \mathrm{hIAPP}_{1-19}\right.$, and rat $\mathrm{IAPP}_{1-19}$ $\left(\right.$ rIAPP $\left.\left._{1-19}\right)\right)$ into DiPoPE lipid bilayers led to a reduction in the temperature required for the transition from the liquid- 
a)

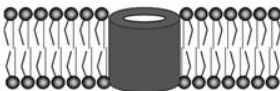

barrel-stave pore

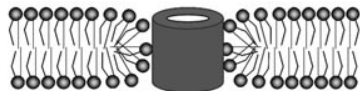

toroidal pore b)
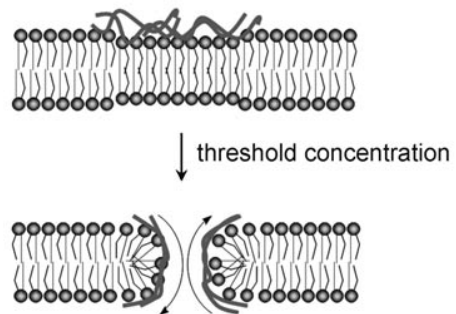

sinking-raft model
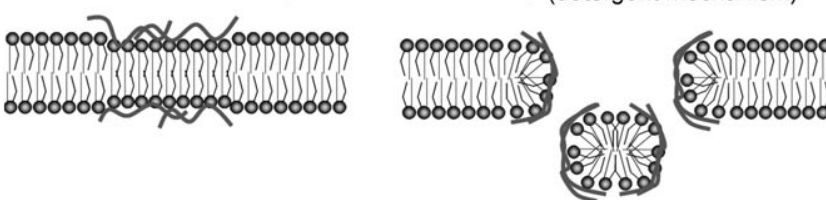

Figure 9. a) Models of barrel-stave and toroidal pores. b) Two-dimensional representations of the sinking-raft and carpet models for membrane permeabilization.

crystalline $\left(\mathrm{L}_{\alpha}\right)$ to the inverted-hexagonal $\left(\mathrm{H}_{\mathrm{II}}\right)$ phase, according to DSC. This result supports the induction of negativemembrane-curvature strain by the peptides. ${ }^{[105]}$ The nonmembrane-permeabilizing peptide rIAPP $_{1-37}$ had a weak influence on the stability of the $\mathrm{H}_{\mathrm{II}}$ phase. Furthermore, ${ }^{31} \mathrm{P}$ chemical shifts demonstrated the preferential binding of the permeabilizing IAPP peptides to highly curved regions of model bicelles, which act as static mimics of the membrane perforations produced in toroidal-pore intermediates. ${ }^{[105]}$ If a toroidal-pore model is operative for IAPP, it is probably not a static structure, and other membrane-disrupting mechanisms probably follow (Figure 9b). In the following section, we highlight results from several research groups that indicate that a detergent-like mechanism is also operative for IAPP, and possibly other amyloidogenic proteins.

\subsection{Are Fibril Formation at Membrane Surfaces and Membrane Permeabilization Concerted Processes? A Detergent Model for Membrane Permeabilization}

In many cases in which lipid membranes promote the misfolding of amyloid proteins into $\beta$-sheet aggregates, a corresponding disruption of membrane structure is also observed. ${ }^{[10 \mathrm{a}, 11 \mathrm{~b}, 106]}$ Such observations indicate that these seemingly separate processes are cooperative and energetically coupled. A recent compelling model for amyloidprotein-related toxicity directly links the processes of amyloid aggregation on membrane surfaces with cell-membrane disruption and the onset of toxicity. ${ }^{[13 a, 107]}$ In other words, as the fibril develops on the membrane surface, the structural integrity of the membrane is simultaneously compromised.

In an elegant study, Engel et al. demonstrated the synchronization of the kinetic profiles for hIAPP-fibril growth, which was monitored by thioflavin T (ThT) fluores- cence, and the induction of dye leakage from coincubated mixed DOPC/DOPS vesicles (Figure 10a). ${ }^{[13 a]}$ The two profiles were characterized by a lag phase of approximately

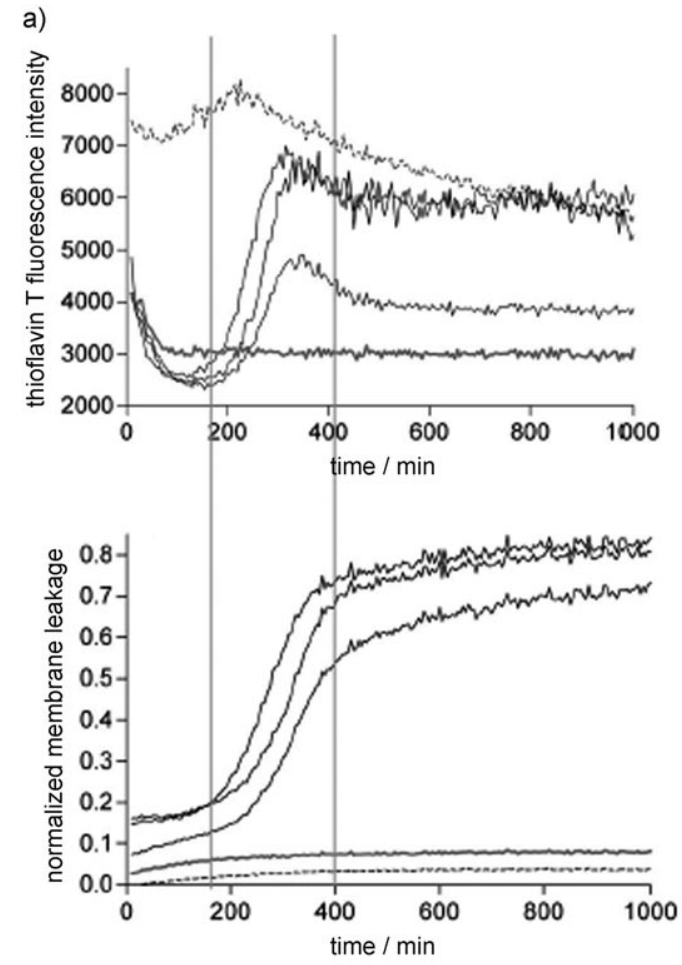

b)

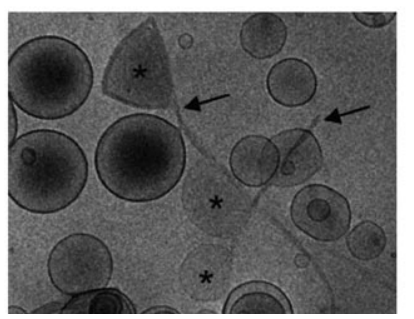

Figure 10. Induction of membrane permeabilization by fibril growth at membrane surfaces (reproduced from reference [13a]). a) Kinetic profiles for hIAPP-fibril formation (top), as monitored by ThT fluorescence, and hIAPP-induced dye leakage from mixed DOPC/DOPS vesicles (bottom). b) Cyro-EM image showing the distortion of vesicles in contact with hIAPP fibrils.

3 hours followed by a sigmoidal transition to hIAPP fibrils and near-complete dye leakage from the vesicles. This result indicates that it is the process of fibril formation on membrane surfaces which is responsible for abolishing the membrane barrier function. Cryogenic electron microscopy (cryo-TEM) images of DOPC/DOPS large unilamellar vesicles (LUVs) coincubated with human IAPP (hIAPP) showed distortion and pinching of regions of the membrane in contact with fibrils (Figure 10b), whereas vesicles incubated in the presence of non-amyloidogenic mouse IAPP (mIAPP) remained unperturbed. ${ }^{[13 a]}$ As a mechanistic model, the authors proposed that IAPP-fibril growth on the membrane occurred concomitantly with a forced change in membrane curvature and weakened lipid packing, which enabled the 
leakage of intravesicular contents (Figure 10b). Interestingly, this notion is consistent with toxicity studies, which have indicated that it is not one specific oligomeric state that induces cell death and toxicity, but rather the dynamic process of fibril formation. ${ }^{[108]}$

Recent results provide strong indications that IAPP on membrane surfaces disintegrates the membrane by extracting lipids and incorporating them into the developing fiber. ${ }^{[13 \mathrm{~b}, \mathrm{c}]}$ Through the use of rhodamine-labeled lipids in giant unilamellar vesicles (GUVs) composed of DOPC, the uptake of fluorescent lipids into coincubated growing IAPP fibrils was imaged by confocal fluorescence microscopy (Figure 11). ${ }^{[13 b]}$
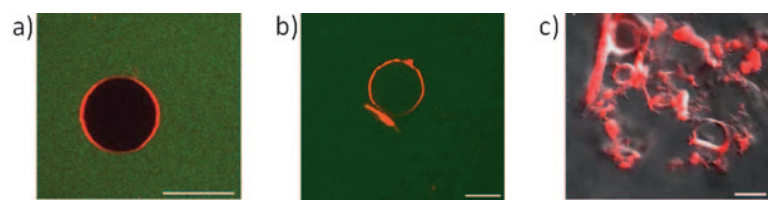

Figure 11. Confocal fluorescence microscopy images of GUVs coincubated with hIAPP (reproduced from reference [13b]); the images demonstrate the uptake of rhodamine-labeled lipids into growing peptide fibrils and eventual vesicle disintegration: a) a GUV before the addition of hIAPP (carboxyfluorescein was added to the extravesicular solvent to demonstrate vesicle-barrier intactness), b) 2-3 min after the addition of hIAPP, and c) 10 min after the addition of hIAPP. Space bars: $25 \mu \mathrm{m}$.

Complete membrane disintegration was visible after coincubation for only 10 minutes (Figure $11 \mathrm{c}$ ). Similarly, when fluorescent boron dipyrromethene (BODIPY) labeled PC in a supported lipid bilayer was used, the extraction and uptake of fluorescent lipids into growing IAPP fibers was visible by confocal microscopy after coincubation for $2-5$ hours. ${ }^{[13 c]}$ After coincubation for 20 hours, the fluorescent lipids were fully incorporated into developed IAPP fibrils. FRET between fiber-bound ThT and BODIPY-labeled PC demonstrated a close association of the extracted lipids with the final fiber. The uptake of rhodamine-labeled lipids obtained from model lipid rafts by BODIPY-labeled IAPP fibers has also been observed by fluorescence microscopy. ${ }^{[109]}$ The extracted membrane fractions could lend thermodynamic stability to the fiber, possibly through electrostatic interactions with exposed positively charged side chains on IAPP or by providing a physical barrier to the proteolytic degradation of developing fibers in vivo. ${ }^{[13 c]}$

These results do not contradict the observed connection between fibril formation on membrane surfaces and membrane disruption, but the demonstrate that the growing IAPP fiber operates through a detergent-like mechanism by extracting lipids and disintegrating the bilayer, rather than by merely pinching the membrane surface. ${ }^{[21]}$ However, membrane distortions may mechanistically precede lipid uptake. By combining the evidence for the detergent-like activity of IAPP with evidence for the induction of toroidalpore structures, one could propose that IAPP follows the carpet model for membrane permeabilization (Figure 9b). The structural analogies between IAPP and $A \beta^{[110]}$ suggest a similar mode of operation for $A \beta$ on membranes. Indeed, TEM images of mixed POPC/POPG vesicles coincubated with $A \beta$ showed the incorporation of lipid vesicles into the final fibril network. ${ }^{[10 \mathrm{a}]}$

In contradiction to the aforementioned arguments, Ramamoorthy and co-workers reported that the membranebinding N-terminal fragment 1-19 of human IAPP, which lacks the amyloidogenic fragment 20-29 and does not fibrillate, induced dye leakage from POPG vesicles to the same extent as the full sequence. ${ }^{[33 \mathrm{~b}]}$ Furthermore, rat IAPP, which does not fibrillate, was also able to permeabilize membranes significantly. ${ }^{[27 b]}$ The authors reasoned that fibril formation is not a necessary factor for membrane disruption, and that these two processes are mechanistically distinct.

\section{Membrane Model Systems and Experimental Tools for Elucidating the Mechanisms of Protein- Induced Membrane Permeabilization}

\subsection{Biological Membranes versus Model Membranes}

Natural cell membranes are intricate structures composed of a lipid bilayer which incorporates globular proteins, receptors, transmembrane channels, and glycoproteins that float in the membrane, as well as regions of varying structural fluidity (Figure 12). ${ }^{[111]}$ Their structural complexity is a reflection of their diverse functions, such as communication between the intra- and extracellular compartments and the selective transport of molecules into and out of cells.

Given the inherent complexity of biological membranes, many scientists rely on structurally and compositionally simplified membrane model systems. These systems offer the opportunity to systematically manipulate the chemical composition and fluidity of the membrane and monitor the resulting changes in protein binding and permeabilization activity. ${ }^{[12]}$ The contrast between model membranes and biological membranes is fundamentally an issue of complexity: model membranes lack components such as integral membrane proteins and polysaccharides that could interfere with experimental results as well as their interpretation. ${ }^{[12]}$ Model membranes are therefore the preferred systems for determining the influence of proteins specifically on lipidic membrane components in a systematically controlled manner. The main disadvantage of model membranes is that a complete picture of the complex array of biochemical processes that influence protein activity cannot be captured by using model systems alone. Rather, model systems provide a platform for the investigation of selected protein-membrane interactions and key mechanistic events that underlie biological activity. They facilitate the interpretation of experimental observations and the development of mechanistic models, and new hypotheses can be later tested in morecomplex biological settings. In the following section, we review the various types of membrane model systems which have been pivotal in providing insight into the mechanisms of amyloidogenic proteins and other membrane-permeabilizing proteins, such as antimicrobial peptides and pore-forming toxins. More-complex and advanced model systems are not 


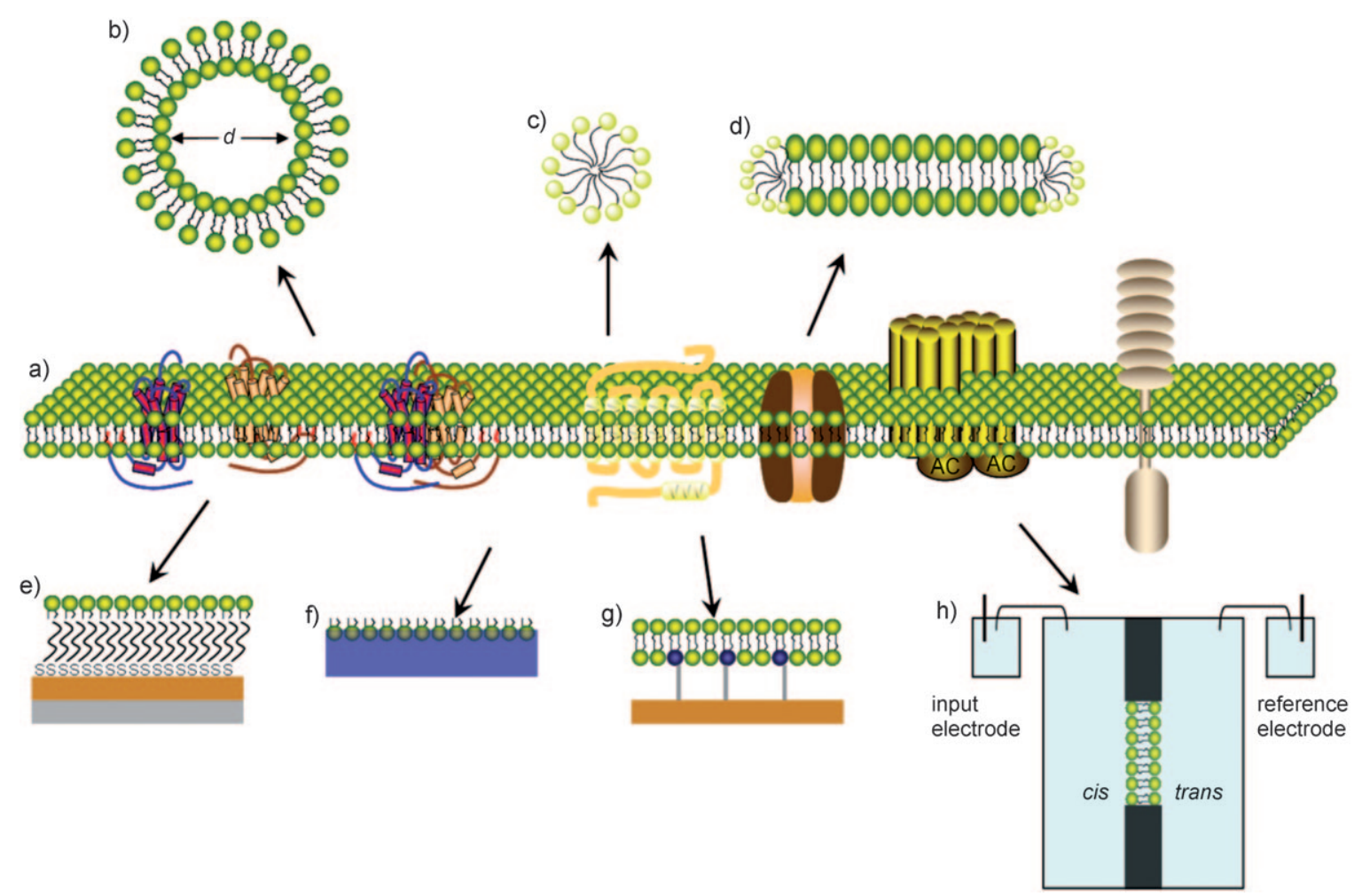

Figure 12. Membrane model systems as derivatives of natural cell membranes: a) illustration of a cell membrane; b) vesicle or liposome; c) micelle; d) bicelle; e) supported lipid monolayer; f) self-assembled lipid monolayer at the air-water interface; g) tethered supported lipid bilayer; h) planar lipid bilayer.

reviewed herein. Instead, we refer the reader to a recent review by Chan and Boxer. ${ }^{[13]}$

\subsection{Classes of Membrane Model Systems 4.2.1. Vesicles, Micelles, and Bicelles}

Vesicles, also referred to as liposomes, are water-filled spherical lipid bilayers with a range of diameters (Figure $12 \mathrm{~b}$ ). There are three main types of vesicles: 1) small unilamellar vesicles (SUVs) with diameters in the range of 20-50 nm, 2) large unilamellar vesicles (LUVs) with diameters of around $100 \mathrm{~nm}$, and 3) giant unilamellar vesicles (GUVs) with diameters in the range of $1-10 \mu \mathrm{m} .{ }^{[12 \mathrm{~b}, 113]}$ The term unilamellar refers to the fact that these vesicles are composed of a single bilayer. Given their spherical shape and water-filled interior, vesicles are thought to be the most biologically relevant mimic of natural cell membranes. For details concerning vesicle preparation, we refer the reader to a recent review. ${ }^{[112 b]}$.

The opportunity to introduce fluorescent and colored dyes into their interiors have made LUVs, in particular, a popular scaffold for monitoring peptide-induced membrane permeabilization through dye-leakage assays, which are described in Section 4.3.2.1. The high curvature of SUVs induces structural tension and high background dye-leakage rates. These systems are thus less attractive for dye-leakage assays. A variety of fluorescently labeled headgroups may also be introduced to enable the investigation of peptide-mem- brane interactions by various fluorescence techniques, such as FRET. ${ }^{[73,114]}$ The physical observation of SUVs and LUVs requires EM techniques including cryo-EM, whereas the large size of GUVs permits the detection of changes in structure and dye permeabilization by light microscopy. ${ }^{[46,115]}$ The binding of tetramethylrhodamine-labeled $\alpha$-synuclein specifically to the surface of anionic GUVs labeled with fluorescent 7-nitrobenz-2-oxa-1,3-diazol-4-yl (NBD) headgroups was demonstrated by fluorescence imaging. ${ }^{[45]}$

Micelles are relatively small detergent or lipid aggregates of approximately $5 \mathrm{~nm}$ in diameter that form above the critical micelle concentration (CMC) of amphiphilic detergents (Figure 12c). They have been used to model the interaction of $A \beta$ with the cell membrane in vitro ${ }^{[69]}$ and to determine the structure of micelle-bound $A \beta,{ }^{[26 b-d, 31 a]} \alpha-$ synuclein, ${ }^{[28 b, 36 b]}$ IAPP ${ }^{[32,116]}$ and antimicrobial peptides ${ }^{[117]}$ by NMR spectroscopy. In contrast to the aqueous interior of vesicles, micelles are filled with the hydrocarbon tails of the detergent (Figure 12c). As a potential drawback, the high curvature of micelles may impose unnaturally curved secondary structures in the micelle-bound proteins and peptides. For example, LUV-bound $\alpha$-synuclein takes on an extended $\alpha$-helix conformation, ${ }^{[28 \mathrm{a}, 34 \mathrm{c}]}$ whereas micelle-bound $\alpha$-synuclein exhibits a helix-turn-helix conformation that is likely to accommodate the highly curved membrane surface (Figure 4). ${ }^{[28 b]}$ The extended helical conformation is thought to more accurately represent membrane-bound $\alpha$-synuclein associated with relatively flat synaptic vesicles in vivo. 
The high curvature of micelles may be decreased by mixing detergents and phospholipids in a certain molar ratio to produce bicelles (bilayer micelles). Bicelles are disc-shaped structures with flat lamellar surfaces and regions of high curvature (Figure 12d) and thus may provide a more accurate mimetic of membrane surfaces in vivo. Indeed, bicelle-bound $\alpha$-synuclein adopts an extended $\alpha$-helix conformation, as determined by ESR distance measurements (Figure 4). ${ }^{[28 d]}$ Furthermore, bicelles align spontaneously in the presence of an external magnetic field; this behavior results in sharply resolved peaks in their NMR spectra. ${ }^{[105]}$ Consequently, bicelles have found utility in NMR-spectroscopy-based structural studies of membrane-binding proteins, including amyloid-forming proteins, such as IAPP. ${ }^{[105,118]}$

\subsubsection{Lipid Monolayers}

A lipid monolayer is perhaps the simplest mimic of the outer leaflet of a biological membrane. A planar supported lipid monolayer is constructed by casting small, unilamellar vesicles onto a hydrophobic self-assembled monolayer anchored on a solid support, such as a gold surface (Figure $12 \mathrm{e}) \cdot{ }^{[119]}$ In this way, the hydrophobic tails of the lipid chains contact the surface, and the polar lipid headgroups are directed toward the aqueous phase. The adsorption or insertion of membrane-binding peptides to or into supported lipid monolayers can then be directly monitored by techniques such as surface plasmon resonance (SPR) and AFM. ${ }^{[119]}$ AFM imaging of a POPC/POPS lipid monolayer on a gold surface has been used to characterize changes or defects in monolayer structure following treatment with wildtype $\alpha$-synuclein, for example. ${ }^{[120]}$

A lipid monolayer can also be constructed at the air-water interface in a Langmuir-Blodgett trough, with the hydrophilic headgroups located in the water subphase and the hydrophobic groups directed toward the air (Figure $12 \mathrm{f}$ ). ${ }^{[121]}$ Surface-pressure measurements of lipid monolayers at the airwater interface provide a measure of membrane lipid packing and have been used to examine the preferential membrane insertion of IAPP monomers over mature fibrils. ${ }^{[122]}$ Furthermore, monolayers of the glycolipid lactosylceramide have been used to establish the minimal fragment of IAPP required for glycolipid binding. ${ }^{[23]} \mathrm{X}$-ray scattering and neutron reflectivity experiments on lipid monolayers at the airwater interface recently enabled the characterization of changes in layer thickness and membrane penetration in the presence of $A \beta$ injected into the aqueous phase..$^{[10]}$

\subsubsection{Model Lipid Bilayers}

Supported lipid bilayers are constructed by Langmuir transfer or vesicle fusion onto a suitable surface. ${ }^{[124,125]}$ To prevent the solid surface from interfering with the membrane properties, a polymer support or a chemical tether is often used to anchor a lipid bilayer on a solid surface (Figure $12 \mathrm{~g}$ ). A bilayer may also be tethered by a labeled membrane protein. Recent reviews discuss the methods used to construct supported lipid bilayers, as well as the advantages and disadvantages of various strategies. ${ }^{[124,125]}$ The nature of the surface depends on the experimental technique. Gold surfaces are used for applications in SPR or ion-channel-activity measurements, ${ }^{[126]}$ whereas mica, silicon, or flat gold are used for applications in AFM. ${ }^{[127]}$ A recent study demonstrated the growth of $A \beta_{26-35}$ fibers parallel to mica-supported POPC lipid bilayers, as imaged by AFM. ${ }^{[128]}$ Supported lipid bilayers have also been employed as model systems to investigate IAPP fibrillation ${ }^{[13 c]}$ and $\alpha$-synuclein clustering on membrane surfaces by fluorescence microscopy. ${ }^{[43]}$

Planar lipid bilayers, also referred to as black lipid membranes, are among the oldest membrane model systems ${ }^{[129]}$ and are the standard systems for single- or multichannel ion-conductance and ion-selectivity experiments. ${ }^{[4 \mathrm{~b}]}$ In a typical experimental setup for conductance measurements, two chambers are filled with a buffer containing electrolytes and are separated by the lipid bilayer located in a micrometer-length aperture in a hydrophobic film, such as Teflon (Figure 12h). ${ }^{[129]}$ An ion-channel- or pore-forming sample is typically inserted into the membrane through the cis chamber, and current flowing through the channel is then recorded as a function of time in response to an applied voltage. Single-channel open and closed states are typically detected in real time as on and off switching of the current, respectively. Ion-channel measurements in planar lipid bilayers have been used to establish the ion-channel activities of $\alpha$ synuclein $^{[65,66,89]}$ and $\mathrm{A} \beta,{ }^{[7 b, 88]}$ as well as polyglutamine- and prion-derived polypeptides. ${ }^{[7 \mathrm{~b}, 76]}$

\subsection{Addressing Mechanistic Questions: Experimental Approaches}

In this section, we highlight how the model systems discussed above may be combined with a multitude of available biophysical techniques to resolve key mechanistic questions regarding the activity of amyloidogenic proteins on membranes. First, biophysical techniques for the detection of the membrane-surface aggregation of proteins and general membrane disruption are presented, followed by techniques that can be used to zero in on structural details of the toxic protein-membrane complex (e.g. the formation of transmembrane pores, pore size, and pore structure). Certain techniques can be used to probe membrane integrity and structural properties, and others to monitor changes in protein structure. Selected examples highlighting the utility of the techniques for the resolution of mechanistic aspects of membrane-active proteins and peptides are given. Many of the highlighted techniques have already generated essential information concerning the membrane-permeabilizing activities of amyloidogenic proteins. In the case of techniques which have not yet been applied to amyloidogenic proteins, we describe how these methods have contributed to our understanding of the molecular mechanisms by which antimicrobial peptides, pore-forming toxins, and other designed membrane-permeating peptides operate on membranes. Given the structural and mechanistic similarities linking amyloidogenic proteins with pore-forming toxins and antimicrobial peptides, the application of these last techniques in the future would certainly advance our current understanding 
of the interaction between amyloidogenic proteins and membranes.

\subsubsection{Does Binding of the Protein/Peptide to the Membrane Surface Accelerate Its Aggregation?}

A variety of techniques may be employed to demonstrate the membrane-mediated catalysis of fibrillogenesis, including imaging methods (AFM and TEM), binding to amyloidspecific dyes, and techniques for monitoring changes in protein size (i.e. gel electrophoresis, size-exclusion chromatography, and light scattering).

In situ AFM was recently used to image the growth of $\mathrm{A} \beta_{26-35}$ fibrils on supported POPC lipid bilayers parallel to the membrane surface. ${ }^{[128]}$ Fibril formation resulting from the incubation of amyloid proteins in the presence of lipid membranes can also be visualized by TEM. ${ }^{[69]}$ Acceleration of the fibril formation of $A \beta(1-40)$ in the presence of ganglioside model membranes was demonstrated by this technique. ${ }^{[26 a]}$ A separate study demonstrated the breaking of $\mathrm{A} \beta(1-40)$ fibrils into smaller soluble oligomers in the presence of a lipid monolayer. ${ }^{[73]}$

Acceleration of the formation of protein aggregates or fibrils by membranes is readily detected by the fluorescence enhancement of the amyloid-specific dye thioflavin $\mathrm{T}$ (ThT). ${ }^{[130]}$ By this technique, it was demonstrated that $\mathrm{A} \beta$ (1-40) aggregation was accelerated in the presence of gangliosides $^{[26 a, 50,106]}$ as well as DPPG-containing vesicles ${ }^{[11 \mathrm{~b}]}$ and SDS micelles. ${ }^{[69]}$

Membrane-induced oligomerization of amyloid proteins has also been monitored by gel electrophoresis. Amyloid proteins, including $\alpha$-synuclein and $A \beta$, have been shown to form higher-order oligomers following reconstitution and extraction from DOPC liposomes by gel electrophoresis. ${ }^{[\mathrm{b}]}$

\subsubsection{Detection of Membrane Permeabilization/Disruption}

The disruption of model-lipid-bilayer structural integrity in the presence of a protein is a first indicator of toxic function. The incorporation of spectroscopic probes either within the interior of vesicles or within the lipid layers themselves provides a number of ways to indirectly probe the weakening of the membrane structure. Other methods include calorimetry or direct membrane imaging by fluorescence microscopy and cryo-EM. Although several of these methods can be adapted to provide more-detailed mechanistic information, as described in the following sections, the techniques discussed herein provide a means to detect general membrane destabilization, but do not resolve the structural and mechanistic details involved in the process.

\subsubsection{Dye-Leakage Assays}

Dye-leakage assays are commonly used to detect changes in membrane permeabilization and disruption of bilayer integrity as a result of peptide or protein binding. ${ }^{[131]}$ In these experiments, LUVs are loaded with fluorescent or colored dyes. The weakening of lipid packing as a result of peptide binding to the membrane enables the intravesicular dye to "leak" to the external buffer medium, where it causes a change in fluorescence or color (Figure 13). ${ }^{[132]}$ The common fluorophores and dyes used in dye-leakage assays are given in Table 1 with the corresponding color or fluorescence changes that occur upon membrane permeabilization, along with key references.

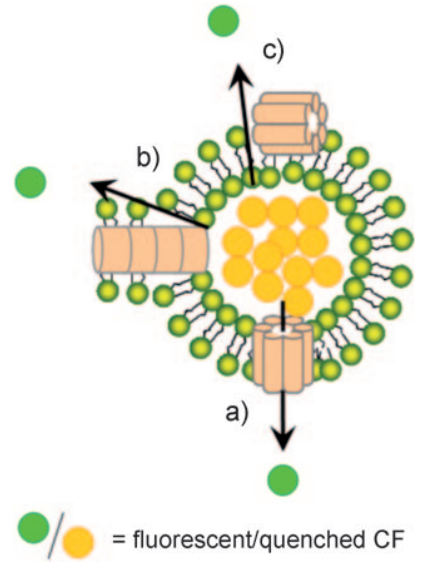

Figure 13. Illustration of the principle of vesicle dye-leakage assays on the basis of the carboxyfluorescein-dequenching assay. Dye leakage can be induced by several mechanisms proposed for amyloid toxicity: a) amyloid-pore formation; b) detergent-like membrane dissolution by growing amyloid fibrils or aggregates; c) nonspecific leakage caused by the binding of amyloid aggregates to the vesicle surface. $\mathrm{CF}=$ carboxyfluorescein.

Among the most common dye-leakage assays for monitoring protein/peptide-induced membrane permeabilization are fluorescence-dequenching assays in which LUVs are loaded with self-quenching fluorophores, such as carboxyfluorescein ${ }^{[85]}$ or calcein, ${ }^{[46,84 b]}$ at high concentrations in the vesicle interior (Figure 13). Dye leakage from the vesicle interior as a result of peptide-induced membrane permeabilization leads to fluorophore dequenching and a dramatic increase in fluorescence owing to fluorophore dilution in the extravesicular buffer. ${ }^{[133]}$ Cation complexation by fluorescent dyes is also a popular method for the detection of protein- or peptide-mediated vesicle permeabilization. The $\mathrm{Tb}^{3+} / \mathrm{DPA}$

Table 1: Dye-leakage assays for membrane permeabilization.

\begin{tabular}{|c|c|c|c|c|c|c|c|}
\hline \multirow[t]{2}{*}{ Dye } & \multirow[t]{2}{*}{ Cation } & \multirow[t]{2}{*}{$\lambda_{\mathrm{ex}} / \lambda_{\mathrm{em}}$} & \multicolumn{4}{|c|}{ Presence of pores } & \multirow[t]{2}{*}{ Ref. } \\
\hline & & & $-^{[a]}$ & $+^{[a]}$ & $-^{[b]}$ & $+^{[b]}$ & \\
\hline $\mathrm{DPA}^{[c]}$ & $\mathrm{Tb}^{3+}$ & $270 / 545$ & - & - & off & on/green & [131] \\
\hline $\mathrm{CF}^{[\mathrm{d}]}$ & - & $492 / 517$ & orange & yellow & off & on/green & [85] \\
\hline ANTS/DPX ${ }^{[\mathrm{e}]}$ & - & $360 / 530$ & - & - & off & on/green & [81] \\
\hline fura-2 & $\mathrm{Ca}^{2+}$ & $340 / 510$ & - & - & off & on/green & [75] \\
\hline arsenazo III & $\mathrm{Ca}^{2+}, \mathrm{Cu}^{2+}$ & 560 & red & blue & - & - & [132] \\
\hline$P V^{[d]}$ & $\mathrm{Cu}^{2+}$ & 450 & yellow & blue & - & - & [132] \\
\hline
\end{tabular}

[a] Color. [b] Fluorescence. [c] DPA = dipicolinic acid. [d] CF=carboxyfluorescein. [e] ANTS=8-amino1,3,6-trisulfonic acid, DPX $=p$-xylenebispyridinium bromide. 
assay relies on the formation of a highly fluorescent ligandreceptor complex between terbium cations $\left(\mathrm{Tb}^{3+}\right)$ and dipicolinic acid (DPA). ${ }^{[1,131]}$ The vesicle is loaded with either $\mathrm{Tb}^{3+}$ or DPA, and the corresponding partner is applied to the vesicle exterior so that the complexing species are fully separated by the bilayer. Peptide-induced permeabilization enables $\mathrm{Tb}^{3+}$ and/or DPA to pass through the membrane and come into contact with its partner to form a highly fluorescent complex and signal vesicle permeabilization. Similarly, vesicles loaded with fura-2, a fluorescent sensor for $\mathrm{Ca}^{2+}$ cations, indicate membrane permeabilization by the formation of a highly fluorescent complex with extravesicular $\mathrm{Ca}^{2+}$.[11a,75] Other colored dyes, such as arsenazo III and pyrocatechol violet, respond to membrane permeabilization upon binding to extravesicular cations, such as $\mathrm{Cu}^{2+}$ or $\mathrm{Ca}^{2+}$, with a dramatic solution-color shift. ${ }^{[132]}$ However, these assays typically require millimolar cation concentrations, which could certainly interfere with the aggregation of amyloid proteins and their interactions with the membrane. ${ }^{[55,62,63,67]}$ In the ANTS/ DPX assay, anionic 8-amino-1,3,6-trisulfonic acid (ANTS) fluorophores are coentrapped with cationic $p$-xylenebispyridinium bromide (DPX) fluorescence quenchers in lipid vesicles. Separation of the ANTS acceptor and DPX donor as a result of peptide-induced leakage is detected as an enhancement in ANTS emission. ${ }^{[81]}$

The main disadvantage of dye-leakage assays is that they do not provide a clear mechanistic picture of peptide-induced membrane disruption, since nearly all mechanisms that cause defects in bilayer structure promote the passage of dyes or ions through the lipid bilayer (Figure 13).

\subsubsection{Lipophilic Fluorescent Probes}

Lipophilic fluorescent probes, such as 1,6-diphenyl-1,3,5hexatriene (DPH) and Laurdan, report changes in membrane fluidity and lipid-chain dynamics as a result of peptide or protein binding. ${ }^{[14,134]}$ Vesicles are prepared by incorporating the fluorescent probe (ca. $1 \mathrm{~mol} \%$ ) within the membrane interior. In the case of DPH, a decrease in fluorescence anisotropy reflects a decrease in membrane ordering. ${ }^{[134]}$ Laurdan is a polarity-sensitive dye that reports the penetration of water molecules into the hydrophobic lipid bilayer as a result of membrane structural destabilization as an increase in fluorescence. ${ }^{[114,134]}$ Interestingly, through the use of these two probes, the addition of monomeric $\alpha$-synuclein to LUVs was found to increase the structural ordering of bilayers. ${ }^{[134]}$ In a later study, decreases in membrane fluidity detected by DPH in the presence of aged ThT-active undefined aggregates of $\alpha$ synuclein suggested that the membrane-disrupting structure is a $\beta$-sheet aggregate. ${ }^{[38]}$ An increase in the lipid structural ordering of POPC vesicles containing cholesterol was also observed following the incorporation of $A \beta(1-42)$ by using Laurdan as a spectroscopic probe. ${ }^{[135]}$

\subsubsection{Fluorescence Microscopy and Cryo-EM of Membranes}

Changes in membrane-surface morphology as a result of peptide or protein injection can be monitored by fluorescence microscopy (FM) ${ }^{[106]}$ Membranes are prepared by incorpo- rating headgroup-labeled fluorescent lipids (less than 1\%). Common fluorescent labels include Texas Red, BODIPY, and rhodamine. In the case of lipid monolayers, FM images of ordered, condensed lipid phases are dark, as dye labels are excluded from these regions owing to steric hindrance, whereas less-ordered phases (liquid-expanded phases) are bright owing to dye partitioning within these regions of the monolayer. ${ }^{[106]}$ Disruption of lipid packing as a result of peptide binding is characterized by a decrease in dark regions and an increase in bright regions in FM images. ${ }^{[106]}$ Membrane defects have been observed by FM in ganglioside-containing membranes upon the addition of $A \beta^{[106]}$ and in PG-containing supported lipid bilayers following the injection of hIAPP. ${ }^{[13 \mathrm{c}]}$ Changes in GUV-surface morphology in the presence of hIAPP $^{[13 b]}$ (Figure 11) and $\alpha$-synuclein ${ }^{[46]}$ have also been imaged by FM.

Cryo-EM also offers an attractive means to image changes in vesicle morphology in response to membrane-active proteins. The advantage of cryo-EM over other imaging techniques is that it does not require sample fixing or stains, and thus preserves the vesicle structure in the hydrated state. Distortions in the structure of DOPC/DOPS vesicles in contact with hIAPP fibers were visualized by cryo-EM (Figure 10b). ${ }^{[13 a]}$

\subsubsection{Does the Permeabilizing Peptide Operate at the Surface or Penetrate the Membrane?}

Peptides may bind to the membrane either by surface association or insertion into the hydrophobic interior. Methods to distinguish surface-acting from membrane-penetrating proteins generally involve the labeling of the peptide or lipid alkyl chains with either paramagnetic or fluorescent reporter molecules that are sensitive to the local solvent environment.

\subsubsection{Site-Directed Spin Labeling of Proteins}

Site-directed spin labeling (SDSL) of proteins or peptides is an electron paramagnetic resonance (EPR) technique which enables structural elucidation of the interaction of proteins or peptides with membranes. ${ }^{[136]}$ Selected residues are mutated to cysteine, either by site-directed mutagenesis or by solid-phase peptide synthesis, and subsequently treated with a nitroxide reagent to introduce a spin label (Figure 14). The accessibility of the labeled residues to polar (nickel ethylenediaminediacetate, NiEDDA) or nonpolar (oxygen)

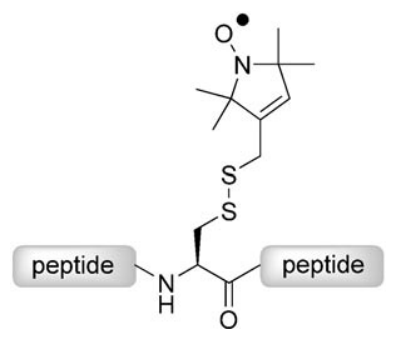

Figure 14. Peptide containing a cysteine residue modified with a nitroxide spin label as an example of the site-directed spin labeling of proteins. 
paramagnetic colliders is used to calculate solvent-accessibility parameters, $\Pi$, for each side chain to generate residue-level information regarding the solvent environment of the membrane-bound protein. Those residues which penetrate the membrane exhibit higher accessibility to nonpolar quenching agents, whereas those which are solvent-exposed have greater accessibility to polar reagents. Thus, the $\Pi$ values for a specified residue for polar versus nonpolar quenching agents are fully out of phase with each other. Accessibility parameters can be further used to calculate depth parameters, $\Phi$ $\left(\Phi=\ln \left(\Pi\left(\mathrm{O}_{2}\right) / \Pi(\mathrm{NiEDDA})\right)\right)$, which are directly proportional to the membrane insertion depth of an individual residue. The SDSL technique has been used to demonstrate the membrane penetration of selected residues of IAPP ${ }^{[27 c]}$ and $\alpha$-synuclein ${ }^{[28 a]}$ (Figures 3 and $4 \mathrm{~b}$ ). More-detailed structural information can be derived by SDSL, such as protein changes in conformation and the formation of water-filled channels, as described in Sections 4.3.4. and 4.3.5.

\subsubsection{Tryptophan Fluorescence}

Tryptophan residues serve as site-specific fluorescent probes for monitoring the degree of membrane penetration of a protein or peptide. Blue shifting of the fluorescence of tryptophan residues of amyloid-forming proteins or peptides indicates peptide penetration into the hydrophobic environment of the bilayer. ${ }^{[137]}$ In many cases, modification of the native sequence to introduce a tryptophan reporter is required. Blue shifting of modified $A \beta 40[Y 10 \mathrm{~W}]$ by $15 \mathrm{~nm}$ was observed upon the addition of anionic DPPC/PG and POPC/PG SUVs, but not in the presence of electrostatically neutral vesicles. ${ }^{[11 \mathrm{~b}]}$

To determine the penetration depth of a membrane-active peptide, spin labels or heavy atoms, such as dibromo or nitroxide derivatives, are introduced at varying depths of the lipids that make up the model membrane (i.e. at the lipid headgroups or at a defined carbon atom in the lipid alkyl chain). ${ }^{[138]}$ Although this method has not yet been applied to amyloidogenic proteins, the pattern of tryptophan-fluorescence quenching as a function of the depth of the quencher can be used to generate angstrom-level resolution of the membrane-penetration depth at a specified tryptophan residue. ${ }^{[138,139]}$ Phosphotidylcholine spin labeling at acyl carbon atoms 5 and 12 was used to establish a penetration depth of 10.5-11 $\AA$ for the single tryptophan side chain for the beevenom-toxin mellitin in both neutral and anionic vesicles. ${ }^{[140]}$ A structural map describing the penetration depths in different regions of the membrane-bound protein can be established by monitoring various tryptophan probes at different positions in the protein. By using brominated spin-labeled fatty acids in PC vesicles, Raja et al. demonstrated that all native tryptophan residues of a pore-forming $\alpha$-toxin from Straphylococcus aureus are positioned at the membranesolvent interface. ${ }^{[137]}$ This technique has also been used to resolve the $\mathrm{pH}$-dependent membrane insertion of the $\mathrm{N}$ terminal region of diphtheria toxin in LUVs containing selectively brominated carbon atoms in the lipid acyl chains. ${ }^{[141]}$
The magnitude of tryptophan protection from collisional quenchers, such as acrylamide ${ }^{[11 \mathrm{~b}]}$ or iodide $\left(\mathrm{I}^{-}\right){ }^{[81]}$ is another measure of penetration into the membrane. If the side-chain residues of the lipid-bound peptide are buried within the bilayer as a result of penetration, tryptophan residues are characteristically protected from exposure to collisional quenchers in the aqueous solvent. In the case of tryptophan-labeled $\mathrm{A} \beta 40[\mathrm{Y} 10 \mathrm{~W}]$, accessibility to collisional quenchers was reduced by $97 \%$ in the presence of DPPC/ PG SUVs owing to membrane insertion of the peptide. ${ }^{[11 b]}$

\subsubsection{Lipid-Monolayer-Expansion Analysis}

Lipid-monolayer-expansion analysis on Langmuir lipid films at the air-water interface has been employed to demonstrate membrane penetration by antimicrobial peptides, toxins, and amyloidogenic proteins. ${ }^{[106,123,142]}$ Surface pressure-area isotherms are determined by spreading a lipid on a subphase free of peptide and compressing the resulting lipid film to a fixed pressure, which is held constant. ${ }^{[121]}$ Following peptide injection into the aqueous subphase, the change in area per lipid molecule $(\triangle A / A)$ is monitored. ${ }^{[121]}$ Peptide penetration into the membrane is reflected as an increase in monolayer surface area as a result of a decrease in lipid packing. Alternatively, membrane dissolution by the peptide would lead to a decrease in the monolayer surface area. Preferential insertion of A $\beta 40$ into anionic monolayers $^{[142 a]}$ and ganglioside membranes ${ }^{[106]}$ has been demonstrated by this technique. The preferential insertion of monomeric structures of hIAPP over fibrillar forms into DOPC/DOPS was established on the basis of pressure-area isotherms on lipid monolayers. ${ }^{[122]}$

\subsubsection{X-Ray- and Neutron-Reflectivity Measurements}

X-ray and neutron reflectivity are analogous techniques which enable the angstrom-level resolution of changes in the thickness and density of lipid monolayers as a result of peptide or protein binding. Reflectivity data are fit to a model, and detailed structural information regarding the protein-membrane complex are extrapolated, such as the depth of protein penetration into the membrane, the dimesionsions of the protein extending into the aqueous phase, and the orientation of the membrane-bound protein. The selective insertion of $A \beta 40$ into anionic lipid monolayers at the airwater interface was demonstrated by the fitting of X-ray- and neutron-reflectivity data, as was the lipid templating of amyloid-fibril formation on anionic membrane surfaces. ${ }^{[10 \mathrm{a}]}$ $\mathrm{X}$-ray-reflectivity data were also recently used to model the time-dependant fibrillation of hIAPP on DOPC/DOPG lipidmonolayer surfaces, including the processes of initial peptide insertion followed by the dissociation of aggregated forms of hIAPP from the membrane surface. ${ }^{[109]}$

\subsubsection{Oriented Solid-State and Solution NMR Spectroscopy and Oriented Circular Dichroism}

Solid-state NMR spectroscopy of ${ }^{15} \mathrm{~N}$-, ${ }^{13} \mathrm{C}$-, or ${ }^{2} \mathrm{H}$-labeled peptides reconstituted into macroscopically oriented lipid 
bilayers has been used to probe the orientation of membranebinding proteins with respect to the membrane normal to evaluate in-plane (surface-bound) versus transmembrane orientations. ${ }^{[143]}$ This technique was used to establish the transmembrane alignment of the pore-forming antimicrobial peptides alamethicin ${ }^{[143 a, 144]}$ and melittin. ${ }^{[143 b]}$. Solution NMR spectroscopy with paramagnetic relaxation enhancement enables the membrane-immersion depth of heavy-atomlabeled protein positions to be determined. This technique was used to confirm the transmembrane alignment of alamethicin. ${ }^{[145]}$ Similarly, oriented circular dichroism with reconstituted proteins in stacked multilayer membranes demonstrated that the cytolytic peptide mellitin can be oriented parallel or perpendicular to the membrane to form a transmembrane pore. ${ }^{[146]}$ However, these techniques have not yet been employed with a view to uncovering the membrane-bound orientations of amyloidogenic proteins.

\subsubsection{What is the Conformation of the Membrane-Bound Protein?}

Membrane-surface-acting $\alpha$ helices and membrane-penetrating $\beta$-barrel or $\alpha$-helical oligomers are among the possible conformations of membrane-active amyloidogenic proteins, antimicrobial peptides, and protein toxins. Besides circular dichroism (CD), which is not discussed herein, moreadvanced techniques, such as SDSL and NMR spectroscopy, enable residue-level resolution of the conformation of the membrane-bound protein.

The periodicity of depth parameters, $\Phi$, obtained by SDSL of each residue across a membrane-bound peptide sequence generates an informative map describing the membranebound conformation of the protein and its orientation with respect to the membrane. ${ }^{[136]}$ For a membrane-associated $\alpha$ helical peptide, the $i$ and $i+4$ residues, which are located on the same face of the helix and are in a similar solvent environment, will have similar $\Phi$ and $\Pi$ values, whereas the $i$ and $i+2$ residues, which are on opposite faces of the helix, one exposed to the solvent and the other in contact with the membrane, will be out of phase with each other. This technique was used for the residue-level resolution of the membrane-bound $\alpha$-helical conformations of hIAPP (Figure 3$)^{[27 c]}$ and $\alpha$-synuclein (Figures $4 b$ and 15)..$^{[28 a]}$

The necessity for spectral resolution has precluded the elucidation of the conformation of peptides in contact with whole cells by high-resolution NMR spectroscopic techniques. Instead, model membranes have proved to be suitable scaffolds for structural determination by NMR spectroscopic methods. Solution NMR spectroscopic techniques have been used to derive the micelle-bound helical conformations of $\mathrm{A} \beta,{ }^{[26 \mathrm{c}, \mathrm{d}, 31 \mathrm{a}]} \mathrm{IAPP}^{[32,33,116]}$ and $\alpha$-synuclein (Figure $\left.4 \mathrm{a}\right) .{ }^{[28 \mathrm{~b}, 147]}$ The structural resolution of membrane-bound $\beta$-sheet aggregates and/or oligomeric transmembrane pores of amyloidforming proteins, which probably form at later stages following membrane binding (Scheme 1), may be more difficult by solution NMR spectroscopic techniques owing to diminished protein solubility. Solid-state NMR spectroscopic methods, which have been used successfully to resolve the structure of amyloid fibrils, may also be useful for determing the
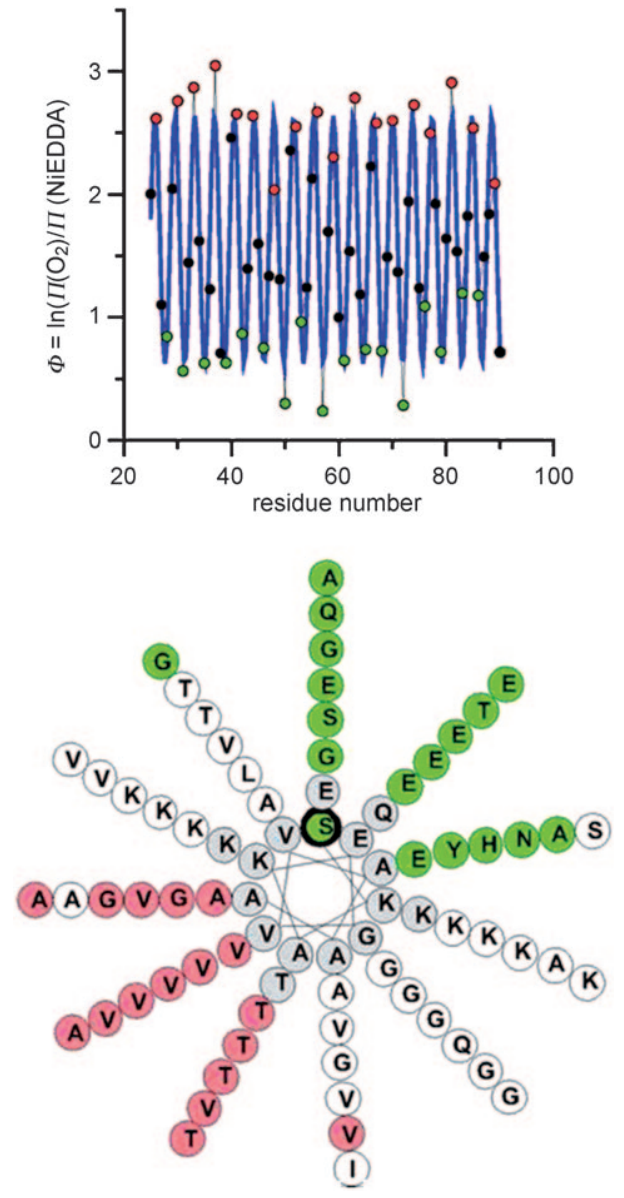

Figure 15. Periodicity of the $\Phi$ values for spin-labeled $\alpha$-synuclein in the presence of lipid vesicles (reproduced from reference [28a]). These values were used to derive the membrane-bound conformation shown in Figure 4 b. Residues with high $\Phi$ values (in red) are lipid-exposed sites. Residues with red labels are on the same membrane-exposed face of the helix (i.e. with $i, i+4$ spacings). Residues in green are on the opposite solvent-exposed face of the helix.

membrane-bound structures of the toxic $\beta$-sheet aggregates of amyloid-forming proteins. ${ }^{[148]}$ Although they have not yet been employed for this purpose, solid-state NMR spectroscopic methods have been used to determine the conformation of other oligomeric pore-forming proteins, such as the $\alpha$ helical alamethin pore. ${ }^{[149]}$ Furthermore, insight into the oligomeric transmembrane $\beta$-barrel structure of the antimicrobial peptide protegrin-1 was also gained by solid-state NMR spectroscopy. ${ }^{[150]}$ Indeed, proposed structural analogies between the pore structure of protegrin- 1 and the $A \beta$ pore suggest the potential of NMR spectroscopic methods for the elucidation of amyloid-pore structures. ${ }^{[148,151]}$

As in the case of SDSL, the advantage of determining protein conformations by NMR spectroscopy is the highresolution structural information it provides, in contrast to more global conformation-detection methods, such as CD. Structural resolution of the membrane-bound structures of amyloid-forming proteins by these methods has, until now, primarily relied on monomeric or heterogenous preparations of amyloid-forming proteins. Atomic-level structures of welldefined oligomeric samples alone or bound to membranes 
have not yet been reported. The lack of structural information pertaining to well-defined oligomeric preparations in contact with membranes primarily results from their transient nature and the difficulties associated with their isolation. ${ }^{[65]}$

\subsubsection{Nonspecific Leakage versus the Formation of Discrete Ion Channels or Pores}

The detection of peptide penetration by the aforementioned techniques does not necessarily demonstrate the formation of a transmembrane pore, as regions or side chains of the protein may only partially insert into the membrane. Evidence for a water-filled channel can be derived from patterns in accessibility parameters derived from SDSL of membrane-binding proteins. ${ }^{[136 c]}$ The measurement of single-ion-channel conductance, however, is probably the most direct technique for identifying true ion-channel or pore activity. ${ }^{[91]}$ Once true pore formation has been established, the pore size can be resolved by the methods described in Section 4.3.6.

Evidence for a water-filled pore may be provided by the pattern of the $\Pi$ values determined from spin-labeled membrane-bound peptides. The $\Pi$ values across a sequence are generally quite uniform in magnitude for a surface-adsorbed protein or peptide; the residues in contact with the membrane, or those that are not in contact with the membrane, display approximately the same $\Pi$ value (Figure 16). ${ }^{[136 c]}$ For a transmembrane water-filled pore

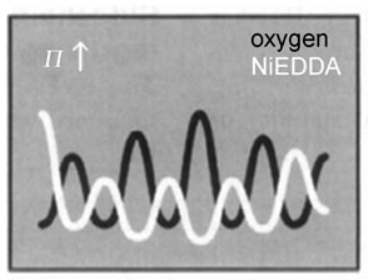

sequence position surface-adsorbed helix

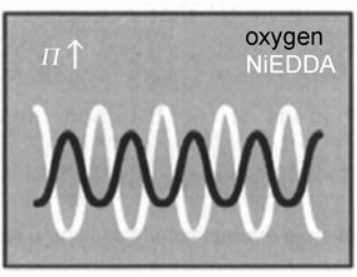

sequence position
Figure 16. Idealized plots of $\Pi$ versus sequence position for a transmembrane water-filled pore (left) and a surface-adsorbed helix (right; reproduced from reference [136c]). The accessibility of residues to nonpolar oxygen paramagnetic colliders is shown in black; their accessibility to polar paramagnetic colliders is shown in white.

water-filled pore, however, residues located close to the pore opening have a higher solvent accessibility, whereas those near the center of the bilayer are in a more nonpolar environment. In the case of a water-filled pore, the magnitude of the $\Pi$ values will be greater near the center of the bilayer in the presence of nonpolar paramagnetic colliders, and greater near the pore openings in the presence of polar paramagnetic colliders (Figure 16). ${ }^{[136 c]}$ This method has been used to identify surface-adsorbed $\alpha$ helices for both $\mathrm{hIAPP}^{[27 \mathrm{c}]}$ and $\alpha$-synuclein. ${ }^{\text {[28a] }}$

The measurement of single-channel conductance induced by the protein or peptide in planar lipid bilayers (Figure 12 h) provides strong evidence for the formation of discrete ion channels or pores. ${ }^{[\mathrm{b}, 91]}$ Typical ion channels stay open for only a fraction of a second to enable the passage of ions through the pore. Current traces as a function of time will reveal current jumps corresponding to the opening and closing of channels if discrete ion channels or pores exist (Figure $7 \mathrm{a}) .^{[129]}$ Voltage gating (i.e. opening or closing of the channel in response to variations in the electric field $)^{[91]}$ and ion specificity are also general features of ion-channel or pore activity. ${ }^{[76]}$ A gradual increase in bilayer conductance, without evidence for open and closed states, is indicative of weakening of the bilayer barrier without the formation of discrete channels or pores. ${ }^{[4 a, b]}$

\subsection{Measurement of Pore Size}

The techniques described in this section may provide further evidence for pore formation by a membrane-permeabilizing protein or peptide and can be used to characterize the pore size. Pore size can be determined by size-selectivity studies in dye-loaded vesicles or by direct imaging methods, such as electron microscopy (EM), atomic force microscopy (AFM), and cryo-EM.

\subsubsection{Size Dependence of Dye Leakage}

Fluorescein isothiocyanate (FITC)-dextrans have been loaded into LUVs and used as pore-size probes. The size of the FITC-dextran is controlled by the size of the dextran polymer. By comparing the leakage rate of small fluorophores, such as calcein or carboxyfluoresin, with that of FITC-dextrans of various sizes through a peptide or protein pore, an approximate pore size can be established. ${ }^{[152]}$ Typically, the small fluorophore-leakage rate is compared with that of FITC-dextrans with molecular weights (MWs) in the approximate range of 4000-40000. Small pores of approximately $2-3 \mathrm{~nm}$ in diameter will only allow smallmolecule fluorophores to pass (e.g. carboxyfluorescein), pores of $5-7 \mathrm{~nm}$ in diameter will allow the passage of FITC-dextrans with molecular weights of 4000-20000, and large pores of $8 \mathrm{~nm}$ in diameter or greater will also allow the passage of FITC-dextrans with a molecular weight of $40000 .{ }^{[152]}$ Nonspecific or detergent-like membrane dissolution by the peptide should not show any size discrimination for dye leakage. Typical bacterial pores do not allow the passage of molecules greater than $600 \mathrm{Da}^{[91]}$ in size owing to the physical restraints of the cavity $(d \approx 0.8-1.1 \mathrm{~nm})$, although pore diameters as large as $15-45 \mathrm{~nm}$ have been reported for the PFTs streptolysin $\mathrm{O}^{[153]}$ and perfingolysin $\mathrm{O} .{ }^{[154]}$ The dyesize threshold for membrane permeabilization by various amyloidogenic proteins has yet to be established. The passage of $\mathrm{Ca}^{2+}$ and dopamine induced by protofibrillar IAPP and $\alpha$ synuclein was shown to be considerably faster than the passage of larger FITC-dextrans; however, although this result suggests size selectivity, the specific pore diameter was not determined. ${ }^{[86]}$

\subsubsection{Electron Microscopy and Atomic Force Microscopy}

For the direct visualization and determination of pore size, EM and AFM are the methods of choice. They have been used extensively to characterize the structural properties of 
on- and off-pathway aggregation intermediates, including amyloid pores, that form during the fibrillization of amyloid proteins in vitro (Scheme 1). Internal pore diameters in the range of $1.5-2.5 \mathrm{~nm}$ were found by EM for protofibrillar species of $\alpha$-synuclein and $A \beta$ (Figure $7 c$ ). ${ }^{[12 a-c]}$ Nanometer resolution of the pore size of a pore-forming peptide or protein incorporated into lipid bilayers is possible by AFM. AFM images have provided high-resolution structural information for several amyloidogenic proteins reconstituted into lipid bilayers on a mica solid support (Figure $7 \mathrm{~b}$ ). ${ }^{[\mathrm{b}, 8 \mathrm{a}]}$

Neutron scattering has been used to determine the inner diameter of the alamethicin pore. ${ }^{[155]}$ Furthermore, cryo-EM images were recently used to measure the pore size of magainin, an antimicrobial peptide. ${ }^{[156]}$ Application of the resulting curve to neutron-scattering theory and simulation provided an average pore size of $8 \mathrm{~nm}$ for the magainin pore. ${ }^{[156]}$ Until now, pores formed from amyloidogenic proteins have not been investigated by these methods.

\subsubsection{Barrel-Stave versus Toroidal Pores}

The classification of a peptide pore as a barrel-stave or toroidal pore is an important step toward structural resolution of the membrane-active species (Figure 9a). The classic example of a barrel-stave-forming antimicrobial peptide is alamethicin, for which important evidence for a barrel-stave pore was provided by single-channel conductance measurements. ${ }^{[146,157]}$ Specifically, discrete conductance levels were observed: a result indicating the formation of a persistent channel. Further support for a barrel-stave model for alamethicin was provided by a combination of solid-state NMR spectroscopy, ${ }^{[143 a, 144,149,158]}$ solution NMR spectroscopy, and MD simulations, all of which indicated that this protein forms a transmembrane $\alpha$-helical pore. ${ }^{[145]}$ Less reproducible ion-channel conductance patterns have been observed for $\alpha$ helical magainin peptides, which are believed to form toroidal pores. The poor reproducibility of the patterns is thought to reflect the fact that toroidal pores are variable rather than discrete structures. ${ }^{[146]}$ Such methods may also be used to deduce structural information regarding amyloid pores.

Other techniques, such as differential scanning calorimetry (DSC) and solid-state NMR spectroscopy on bicelle models, were employed to detect the induction of membrane curvature, which is characteristic of toroidal-pore intermediates. ${ }^{[105]} \mathrm{A}$ shift in the phase transition between the liquidcrystalline $\left(\mathrm{L}_{\alpha}\right)$ and inverted-hexagonal $\left(\mathrm{H}_{\mathrm{II}}\right)$ phase in DiPoPE membranes in the presence of IAPP peptides, as monitored by DSC, supported the induction of negativemembrane-curvature strain and possible toroidal-pore structures. ${ }^{[105]}$ The preferential binding of peptides to the highly curved regions of model bicelle membranes provides support for membrane permeabilization through the formation of toroidal pores. For example, the observation of headgroup ${ }^{31} \mathrm{P}$ chemical shifts at bicelle curved perforations in the presence of IAPP indicated the induction of toroidal-pore structures by the protein. ${ }^{[105]}$

Spectroscopic assays are also available that can provide evidence for toroidal-pore intermediates. The lipid flip-flop assay detects the translocation of lipids from the outer to the inner membrane leaflet, as promoted by the formation of toroidal pores. ${ }^{[117,152,159]}$ Coupling of the lipid flip-flop assay with dye leakage from dye-loaded vesicles indicates the formation of toroidal pores. This technique has not yet been applied to mechanistic studies of amyloid-forming proteins.

\subsubsection{Detection of Membrane Fusion}

Membrane permeabilization may also occur by peptideor protein-induced membrane fusion. It is not likely that a fusion mechanism alone is responsible for membrane destabilization in the case of amyloidogenic proteins, as even fusion complexes can be associated with the formation of pores. ${ }^{[160]}$ The process of peptide/protein-induced fusion involves: 1) the tethering of membranes, 2) membrane destabilization, during which the contents of a bilayer may leak, and 3) fusion to larger membrane structures. ${ }^{[161]}$

Membrane fusogenic activity has been demonstrated on several occasions with $A \beta^{[10 a, 106,162]}$ and the amyloidogenic prion-protein fragment $\operatorname{Pr} \mathrm{P}(106-126),{ }^{[163]}$ and has been implicated for $\alpha$-synuclein membrane activity. ${ }^{[164]}$ Vesicle-fusion assays monitor vesicle fusion spectroscopically and have been employed to demonstrate the membrane fusogenic activity of an $\mathrm{A} \beta$ fragment. ${ }^{[162 \mathrm{~b}]}$ Typical vesicle-fusion assays rely on FRET with fluorophore-labeled lipid vesicles ${ }^{[163,165]}$ or coremixing assays. ${ }^{[166]}$ Dynamic light scattering also offers a means of determining changes in the vesicle hydrodynamic radius as a result of peptide-induced fusion, and has recently been used to demonstrate increases in vesicle radius upon incubation with $A \beta .^{[10 a, 106]}$ Furthermore, the formation of larger vesicles by peptide-induced vesicle fusion may be imaged directly by fluorescence microscopy with labeled lipids ${ }^{[167]}$ or by cryoEM.

\section{Summary and Outlook}

Substantial experimental evidence indicates that the toxicity of amyloid-forming proteins is related to their interaction with cell membranes. A connection has been observed between membrane-induced fibril formation and amyloidogenic-protein-induced membrane disruption. The process of amyloid-fibril formation is enhanced at the surface of anionic membranes, by the promotion of the transformation from native soluble protein $\rightarrow \alpha$ helix $\rightarrow$ prefibrillar $\beta$ sheet oligomers. A likely target for these prefibrillar aggregates is the cell membrane itself, as the prefibrillar aggregates exhibit higher membrane-permeabilizing activity than either monomeric or fibrillar forms. The direct visualization of annular porelike protofibrillar oligomers with striking morphological resemblance to the membrane-active structures of the pore-forming toxins, as well as the demonstration of channel-like conductance states in several amyloid-forming proteins, supports the hypothesis that a porelike mechanism underlies the toxicity of amyloidogenic proteins. However, pore activity may only represent a fraction of the permeabilization process. Recent studies with IAPP, in particular, demonstrated complete membrane degradation by lipid extraction and uptake into growing IAPP fibrils, in analogy 
with the detergent-like carpet model proposed for certain antimicrobial peptides.

Although further studies are required, we can begin to construct a mechanistic model of the permeabilization process by integrating the results presented herein. Prefibrillar aggregates derived from $\alpha$-helical precursors bind to or form on the membrane and form transmembrane $\beta$-sheet annular structures that enable the unregulated leakage of cellular contents through the pore. At later stages of aggregation, the developing fiber begins to extract lipid molecules from the membrane. This process eventually results in complete loss of the membrane barrier function. This behavior could explain why the process of fibril formation, rather than a discrete intermediate, has sometimes been associated with membrane disruption and toxicity in some reports.

Many of the studies presented herein were based on monomeric or aged heterogenous samples with an ill-defined structure and oligomeric state. Given the complexity of amyloid-fibril formation, the vast number of intermediate oligomeric states that exist in exchange with one another, and the lack of knowledge concerning the three-dimensional (3D) structures of the various intermediate states, complete coherence of experimental results from different studies may not be possible unless standardized protein-preparation procedures are adopted. If some of these discrepancies are to be resolved, the initial steps should be to optimize the isolation of the dominant intermediate oligomeric species, if possible, and resolve their 3D structures. Mechanistic studies and assays may then be applied to these samples to identify the species with the highest membrane-permeabilizing activity and resolve the molecular process of membrane disruption. Indeed, it may be that not one oligomeric state, but rather the dynamic exchange that occurs during fibril formation, is responsible for membrane disruption, as has been suggested in several recent articles.

Ongoing studies with artificial membrane model systems have begun to contribute valuable insight into the mechanisms by which amyloidogenic proteins interact with membranes and induce cell toxicity. These studies have uncovered several analogies between amyloid-forming proteins and the pore-forming toxins and antimicrobial peptides. Thus, we can employ techniques that have previously provided mechanistic information regarding the activity of the pore-forming toxins and antimicrobial peptides to fill the knowledge gap that exists for the amyloid-forming proteins, which are not so wellcharacterized. It is our hope that this Review will further stimulate research toward this end.

\section{Abbreviations}

DiPoPE dipalmitoleoylphosphatidylethanolamine DMPC 1,2-dimyristoyl-sn-glycero-3-phosphocholine

DMPG 1,2-dimyristoyl-sn-glycero-3-phospho(1'rac-glycerol)

DPC dodecyl phosphocholine
DPPC

1,2-dipalmitoyl-sn-glycero-3-phosphocholine

DPPG 1,2-dipalmitoyl-sn-glycero-3-phospho(1'rac-glycerol)

DOPA 1,2-dioleoyl-sn-glycero-3-phosphate

DOPC 1,2-dioleoyl-sn-glycero-3-phosphocholine

DOPG 1,2-dioleoyl-sn-glycero-3-phospho(1'-racglycerol)

DOPS 1,2-dioleoyl-sn-glycero-3-phospho-L-serine

POPC 1-palmitoyl-2-oleoyl-sn-glycero-3-phosphocholine

POPG 1-palmitoyl-2-oleoyl-sn-glycero-3-phospho(1'-rac-glycerol)

POPS 1-palmitoyl-2-oleoyl-sn-glycero-3-phospho-L-serine

PC phosphatidylcholine

PG phosphatidylglycerol

PS phosphatidylserine

SDS sodium dodecyl sulfate

We thank Prof. Ralf Langen, Prof. Maarten Engel, Prof. Ratnesh Lal, Prof. Eliezer Masliah, Prof. Ruth Nussinov, and Prof. Wei-Ping Gai for providing permission to use some of their data in this Review. Prof. Lashuel thanks Prof. Peter T. Lansbury and Prof. Thomas Walz for their contribution to our research in this field and for their support and thoughtful discussions on this topic. Our research in this field was supported by funding from the Ecole Polytechnique Fédérale de Lausanne (EPFL) and a grant from the Swiss National Science Foundation (H.A.L., FE 310000-110027).

Received: November 26, 2009

Published online: July 12, 2010

[1] F. M. LaFerla, K. N. Green, S. Oddo, Nat. Rev. Neurosci. 2007, $8,499$.

[2] M. G. Spillantini, M. L. Schmidt, V. M. Lee, J. Q. Trojanowski, R. Jakes, M. Goedert, Nature 1997, 388, 839.

[3] P. Westermark, C. Wernstedt, E. Wilander, D. W. Hayden, T. D. O'Brien, K. H. Johnson, Proc. Natl. Acad. Sci. USA 1987, 84, 3881.

[4] a) R. Kayed, Y. Sokolov, B. Edmonds, T. M. McIntire, S. C. Milton, J. E. Hall, C. G. Glabe, J. Biol. Chem. 2004, 279, 46363; b) Y. Sokolov, J. A. Kozak, R. Kayed, A. Chanturiya, C. Glabe, J. E. Hall, J. Gen. Physiol. 2006, 128, 637; c) L. Haataja, T. Gurlo, C. J. Huang, P. C. Butler, Endocr. Rev. 2008, 29, 303.

[5] a) D. M. Walsh, I. Klyubin, J. V. Fadeeva, W. K. Cullen, R. Anwyl, M. S. Wolfe, M. J. Rowan, D. J. Selkoe, Nature 2002, 416, 535; b) S. Lesné, M. T. Koh, L. Kotilinek, R. Kayed, C. G. Glabe, A. Yang, M. Gallagher, K. H. Ashe, Nature 2006, 440, 352.

[6] D. L. Pountney, N. H. Voelcker, W. P. Gai, Neurotoxic. Res. $\mathbf{2 0 0 5}, 7,59$.

[7] a) H. A. Lashuel, P. T. Lansbury, Jr., Q. Rev. Biophys. 2006, 39, 167; b) A. Quist, I. Doudevski, H. Lin, R. Azimova, D. Ng, B. Frangione, B. Kagan, J. Ghiso, R. Lal, Proc. Natl. Acad. Sci. USA 2005, 102, 10427.

[8] a) H. Lin, R. Bhatia, R. Lal, FASEB J. 2001, 15, 2433; b) H. B. Pollard, N. Arispe, E. Rojas, Cell. Mol. Neurobiol. 1995, 15, 513.

[9] A. Relini, O. Cavalleri, R. Rolandi, A. Gliozzi, Chem. Phys. Lipids 2009, 158, 1. 
[10] a) E. Y. Chi, C. Ege, A. Winans, J. Majewski, G. Wu, K. Kjaer, K. Y. Lee, Proteins Struct. Funct. Genet. 2008, 72, 1; b) C. Aisenbrey, T. Borowik, R. Byström, M. Bokvist, F. Lindström, H. Misiak, M.-A. Sani, G. Gröbner, Eur. Biophys. J. 2008, 37, 247

[11] a) M. J. Volles, S. J. Lee, J. C. Rochet, M. D. Shtilerman, T. T. Ding, J. C. Kessler, P. T. Lansbury, Jr., Biochemistry 2001, 40, 7812; b) P. T. Wong, J. A. Schauerte, K. C. Wisser, H. Ding, E. L. Lee, D. G. Steel, A. Gafni, J. Mol. Biol. 2009, 386, 81.

[12] a) H. A. Lashuel, P. T. Lansbury, Q. Rev. Biophys. 2006, 39, 167; b) H. A. Lashuel, D. Hartley, B. M. Petre, T. Walz, P. T. Lansbury, Jr., Nature 2002, 418, 291; c) H. A. Lashuel, B. M. Petre, J. Wall, M. Simon, R. J. Nowak, T. Walz, P. T. Lansbury, Jr., J. Mol. Biol. 2002, 322, 1089; d) R. Capone, F. G. Quiroz, P. Prangkio, I. Saluja, A. M. Sauer, M. R. Bautista, R. S. Turner, J. Yang, M. Mayer, Neurotoxic. Res. 2009, 16, 1; e) B. L. Kagan, R. Azimov, R. Azimova, J. Membr. Biol. 2004, 202, 1; f) N. Arispe, E. Rojas, H. B. Pollard, Proc. Natl. Acad. Sci. USA 1993, 90, 567; g) H. B. Pollard, E. Rojas, N. Arispe, Ann. N. Y. Acad. Sci. 1993, 695, 165.

[13] a) M. F. Engel, L. Khemtemourian, C. C. Kleijer, H. J. Meeldijk, J. Jacobs, A. J. Verkleij, B. de Kruijff, J. A. Killian, J. W. Hoppener, Proc. Natl. Acad. Sci. USA 2008, 105, 6033; b) E. Sparr, M. F. Engel, D. V. Sakharov, M. Sprong, J. Jacobs, B. de Kruijff, J. W. Hoppener, J. A. Killian, FEBS Lett. 2004, 577, 117; c) Y. A. Domanov, P. K. Kinnunen, J. Mol. Biol. 2008, 376, 42.

[14] J. N. Rao, Y. E. Kim, L. S. Park, T. S. Ulmer, J. Mol. Biol. 2009, $390,516$.

[15] F. Chiti, C. M. Dobson, Annu. Rev. Biochem. 2006, 75, 333.

[16] R. M. Murphy, Biochim. Biophys. Acta Biomembr. 2007, 1768, 1923.

[17] R. Sabaté, J. Estelrich, J. Phys. Chem. B 2005, 109, 11027.

[18] P. Seubert, C. Vigo-Pelfrey, F. Esch, M. Lee, H. Dovey, D. Davis, S. Sinha, M. Schiossmacher, J. Whaley, C. Swindlehurst, R. McCormack, R. Wolfert, D. Selkoe, I. Lieberburg, D. Schenk, Nature 1992, 359, 325.

[19] J. D. Knight, A. D. Miranker, J. Mol. Biol. 2004, 341, 1175.

[20] M. R. Wilson, J. J. Yerbury, S. Poon, Mol. Biosyst. 2008, 4, 42.

[21] J. A. Hebda, A. D. Miranker, Annu. Rev. Biophys. 2009, 38, 125.

[22] R. Byström, C. Aisenbrey, T. Borowik, M. Bokvist, F. Lindström, M. A. Sani, A. Olofsson, G. Gröbner, Cell Biochem. Biophys. 2008, 52, 175.

[23] M. Bokvist, G. Gröbner, J. Am. Chem. Soc. 2007, 129, 14848.

[24] S. A. Jayasinghe, R. Langen, Biochim. Biophys. Acta Biomembr. 2007, 1768, 2002.

[25] A. Abedini, D. P. Raleigh, Protein Eng. Des. Sel. 2009, 22, 453.

[26] a) T. Okada, M. Wakabayashi, K. Ikeda, K. Matsuzaki, J. Mol. Biol. 2007, 371, 481; b) T. G. Fletcher, D. A. Keire, Protein Sci. 1997, 6, 666; c) P. K. Mandal, J. W. Pettegrew, Neurochem. Res. 2004, 29, 2267; d) H. Shao, S. Jao, K. Ma, M. G. Zagorski, J. Mol. Biol. 1999, 285, 755 .

[27] a) J. A. Williamson, J. P. Loria, A. D. Miranker, J. Mol. Biol. 2009, 393, 383; b) J. D. Knight, J. A. Hebda, A. D. Miranker, Biochemistry 2006, 45, 9496; c) M. Apostolidou, S. A. Jayasinghe, R. Langen, J. Biol. Chem. 2008, 283, 17205; d) S. A. Jayasinghe, R. Langen, Biochemistry 2005, 44, 12113.

[28] a) C. C. Jao, B. G. Hegde, J. Chen, I. S. Haworth, R. Langen, Proc. Natl. Acad. Sci. USA 2008, 105, 19666; b) T. S. Ulmer, A. Bax, N. B. Cole, R. L. Nussbaum, J. Biol. Chem. 2005, 280, 9595; c) M. Drescher, F. Godschalk, G. Veldhuis, B. D. van Rooijen, V. Subramaniam, M. Huber, ChemBioChem 2008, 9, 2411; d) E. R. Georgieva, T. F. Ramlall, P. P. Borbat, J. H. Freed, D. Eliezer, J. Am. Chem. Soc. 2008, 130, 12856.

[29] D. H. Lopes, A. Meister, A. Gohlke, A. Hauser, A. Blume, R. Winter, Biophys. J. 2007, 93, 3132.
[30] M. D. Kirkitadze, M. M. Condron, D. B. Teplow, J. Mol. Biol. 2001, 312, 1103.

[31] a) M. Coles, W. Bicknell, A. A. Watson, D. P. Fairlie, D. J. Craik, Biochemistry 1998, 37, 11064; b) T. Kohno, K. Kobayashi, T. Maeda, K. Sato, A. Takashima, Biochemistry 1996, 35, 16094.

[32] S. M. Patil, S. Xu, S. R. Sheftic, A. T. Alexandrescu, J. Biol. Chem. 2009, 284, 11982.

[33] a) R. P. Nanga, J. R. Brender, J. Xu, G. Veglia, A. Ramamoorthy, Biochemistry 2008, 47, 12689; b) J. R. Brender, E. L. Lee, M. A. Cavitt, A. Gafni, D. G. Steel, A. Ramamoorthy, J. Am. Chem. Soc. 2008, 130, 6424.

[34] a) L. Kjaer, L. Giehm, T. Heimburg, D. Otzen, Biophys. J. 2009, 96, 2857; b) M. Drescher, G. Veldhuis, B. D. van Rooijen, S. Milikisyants, V. Subramaniam, M. Huber, J. Am. Chem. Soc. 2008, 130, 7796; c) A. J. Trexler, E. Rhoades, Biochemistry 2009, 48, 2304; d) D. Eliezer, E. Kutluay, R. Bussell, Jr., G. Browne, J. Mol. Biol. 2001, 307, 1061.

[35] K. Vamvaca, M. J. Volles, P. T. Lansbury, Jr., J. Mol. Biol. 2009, 389,413

[36] a) M. Mihajlovic, T. Lazaridis, Proteins Struct. Funct. Genet. 2008, 70, 761; b) R. Bussell, Jr., D. Eliezer, J. Mol. Biol. 2003, $329,763$.

[37] M. J. Volles, P. T. Lansbury, Jr., J. Mol. Biol. 2007, 366, 1510.

[38] D. P. Smith, D. J. Tew, A. F. Hill, S. P. Bottomley, C. L. Masters, K. J. Barnham, R. Cappai, Biochemistry 2008, 47, 1425.

[39] M. Zhu, A. L. Fink, J. Biol. Chem. 2003, 278, 16873.

[40] H. J. Lee, C. Choi, S. J. Lee, J. Biol. Chem. 2002, 277, 671.

[41] M. Necula, C. N. Chirita, J. Kuret, J. Biol. Chem. 2003, 278, 46674.

[42] a) K. Matsuzaki, Biochim. Biophys. Acta Biomembr. 2007, 1768, 1935; b) C. H. Davis, M. L. Berkowitz, Biophys. J. 2009, 96, 785.

[43] A. P. Pandey, F. Haque, J. C. Rochet, J. S. Hovis, Biophys. J. 2009, $96,540$.

[44] F. Evers, C. Jeworrek, S. Tiemeyer, K. Weise, D. Sellin, M. Paulus, B. Struth, M. Tolan, R. Winter, J. Am. Chem. Soc. 2009, 131, 9516.

[45] M. Stöckl, P. Fischer, E. Wanker, A. Herrmann, J. Mol. Biol. 2008, 375, 1394.

[46] B. D. van Rooijen, M. M. Claessens, V. Subramaniam, FEBS Lett. 2008, 582, 3788.

[47] J. A. Allen, R. A. Halverson-Tamboli, M. M. Rasenick, Nat. Rev. Neurosci. 2007, 8, 128

[48] Y. Tamai, S. Matsukawa, M. Satake, J. Biochem. 1971, 69, 235.

[49] a) D. R. Taylor, N. M. Hooper, Mol. Membr. Biol. 2006, 23, 89; b) S. I. Kim, J. S. Yi, Y. G. Ko, J. Cell. Biochem. 2006, 99, 878; c) T. J. Pinheiro, Chem. Phys. Lipids 2006, 141, 66.

[50] T. Okada, K. Ikeda, M. Wakabayashi, M. Ogawa, K. Matsuzaki, J. Mol. Biol. 2008, 382, 1066.

[51] K. Yanagisawa, Biochim. Biophys. Acta Biomembr. 2007, 1768, 1943.

[52] K. Matsuzaki, T. Noguch, M. Wakabayashi, K. Ikeda, T. Okada, Y. Ohashi, M. Hoshino, H. Naiki, Biochim. Biophys. Acta Biomembr. 2007, 1768, 122.

[53] M. Wakabayashi, K. Matsuzaki, FEBS Lett. 2009, 583, 2854.

[54] F. Re, S. Sesana, A. Barbiroli, F. Bonomi, E. Cazzaniga, E. Lonati, A. Bulbarelli, M. Masserini, FEBS Lett. 2008, 582, 215.

[55] C. C. Curtain, F. E. Ali, D. G. Smith, A. I. Bush, C. L. Masters, K. J. Barnham, J. Biol. Chem. 2003, 278, 2977.

[56] L. Qiu, A. Lewis, J. Como, M. W. Vaughn, J. Huang, P. Somerharju, J. Virtanen, K. H. Cheng, Biophys. J. 2009, 96, 4299.

[57] C. Cecchi, D. Nichino, M. Zampagni, C. Bernacchioni, E. Evangelisti, A. Pensalfini, G. Liguri, A. Gliozzi, M. Stefani, A. Relini, Biochim. Biophys. Acta Biomembr. 2009, 1788, 2204.

[58] W. J. Cho, S. Trikha, A. M. Jeremic, J. Mol. Biol. 2009, 393, 765. 
[59] E. C. Hirsch, J. P. Brandel, P. Galle, F. Javoy-Agid, Y. Agid, J. Neurochem. 1991, 56, 446.

[60] M. A. Lovell, J. D. Robertson, W. J. Teesdale, J. L. Campbell, W. R. Markesbery, J. Neurol. Sci. 1998, 158, 47.

[61] A. Gaeta, R. C. Hider, Br. J. Pharmacol. 2005, 146, 1041.

[62] E. House, J. Collingwood, A. Khan, O. Korchazkina, G. Berthon, C. Exley, J. Alzheimer's Dis. 2004, 6, 291.

[63] a) V. N. Uversky, J. Li, A. L. Fink, J. Biol. Chem. 2001, 276, 44284; b) Bharathi, S. S. Indi, K. S. J. Rao, Neurosci. Lett. 2007 $424,78$.

[64] R. Lowe, D. L. Pountney, P. H. Jensen, W. P. Gai, N. H. Voelcker, Protein Sci. 2004, 13, 3245.

[65] H.-Y. Kim, M.-K. Cho, A. Kumar, E. Maier, C. Siebenhaar, S Becker, C. O. Fernandez, H. A. Lashuel, R. Benz, A. Lange, M. Zweckstetter, J. Am. Chem. Soc. 2009, 131, 17482.

[66] M. Kostka, T. Hogen, K. M. Danzer, J. Levin, M. Habeck, A Wirth, R. Wagner, C. G. Glabe, S. Finger, U. Heinzelmann, P. Garidel, W. Duan, C. A. Ross, H. Kretzschmar, A. Giese, $J$. Biol. Chem. 2008, 283, 10992.

[67] a) J. D. Gehman, C. C. O'Brien, F. Shabanpoor, J. D. Wade, F. Separovic, Eur. Biophys. J. 2008, 37, 333; b) T. L. Lau, E. E. Ambroggio, D. J. Tew, R. Cappai, C. L. Masters, G. D. Fidelio, K. J. Barnham, F. Separovic, J. Mol. Biol. 2006, 356, 759.

[68] D. P. Smith, D. G. Smith, C. C. Curtain, J. F. Boas, J. R. Pilbrow, G. D. Ciccotosto, T.-L. Lau, D. J. Tew, K. Perez, J. D. Wade, A. I. Bush, S. C. Drew, F. Separovic, C. L. Masters, R. Cappai, K. J. Barnham, J. Biol. Chem. 2006, 281, 15145.

[69] V. Rangachari, B. D. Moore, D. K. Reed, L. K. Sonoda, A. W. Bridges, E. Conboy, D. Hartigan, T. L. Rosenberry, Biochem istry 2007, 46, 12451.

[70] Y. Shai, Biopolymers 2002, 66, 236.

[71] a) M. N. Melo, R. Ferre, M. A. Castanho, Nat. Rev. Microbiol. 2009, 7, 245; b) H. W. Huang, Biochemistry 2000, 39, 8347

[72] I. C. Martins, I. Kuperstein, H. Wilkinson, E. Maes, M. Vanbrabant, W. Jonckheere, P. Van Gelder, D. Hartmann, R. D'Hooge, B. De Strooper, J. Schymkowitz, F. Rousseau, EMBO J. 2008, 27, 224

[73] M. J. O. Widenbrant, J. Rajadas, C. Sutardja, G. G. Fuller, Biophys. J. 2006, 91, 4071

[74] a) N. Arispe, H. B. Pollard, E. Rojas, Proc. Natl. Acad. Sci. USA 1993, 90, 10573; b) N. Arispe, H. B. Pollard, E. Rojas, Proc. Natl. Acad. Sci. USA 1996, 93, 1710; c) T. A. Mirzabekov, M. C. Lin, B. L. Kagan, J. Biol. Chem. 1996, 271, 1988; d) Y. Hirakura M. C. Lin, B. L. Kagan, J. Neurosci. Res. 1999, 57, 458.

[75] M. J. Volles, P. T. Lansbury, Jr., Biochemistry 2002, 41, 4595.

[76] H. Monoi, S. Futaki, S. Kugimiya, H. Minakata, K. Yoshihara, Biophys. J. 2000, 78, 2892.

[77] a) J. I. Kourie, A. Culverson, J. Neurosci. Res. 2000, 62, 120; b) J. I. Kourie, P. V. Farrelly, C. L. Henry, J. Neurosci. Res. 2001, 66, 214.

[78] a) M. P. Mattson, S. L. Chan, J. Mol. Neurosci. 2001, 17, 205; b) P. Hajieva, C. Kuhlmann, H. J. Luhmann, C. Behl, Neurosci. Lett. 2009, 451, 119.

[79] H. A. Lashuel, D. M. Hartley, B. M. Petre, J. S. Wall, M. N. Simon, T. Walz, P. T. Lansbury, Jr., J. Mol. Biol. 2003, 332, 795.

[80] a) D. Eliezer, J. Gen. Physiol. 2006, 128, 631; b) G. Valincius, F. Heinrich, R. Budvytyte, D. J. Vanderah, D. J. McGillivray, Y Sokolov, J. E. Hall, M. Losche, Biophys. J. 2008, 95, 4845.

[81] J. M. Rausch, J. R. Marks, R. Rathinakumar, W. C. Wimley, Biochemistry 2007, 46, 12124.

[82] B. Bechinger, K. Lohner, Biochim. Biophys. Acta Biomembr. 2006, 1758,1529

[83] C. G. Glabe, J. Biol. Chem. 2008, 283, 29639

[84] a) Y. Porat, S. Kolusheva, R. Jelinek, E. Gazit, Biochemistry 2003, 42, 10971; b) L. Pieri, M. Bucciantini, P. Guasti, J. Savistchenko, R. Melki, M. Stefani, Biophys. J. 2009, 96, 3319.
[85] W. Qi, A. Zhang, T. A. Good, E. J. Fernandez, Biochemistry 2009, 48, 8908 .

[86] M. Anguiano, R. J. Nowak, P. T. Lansbury, Jr., Biochemistry 2002, 41, 11338 .

[87] Y. Yoshiike, R. Kayed, S. C. Milton, A. Takashima, C. G. Glabe, NeuroMolecular Med. 2007, 9, 270.

[88] M. R. de Planque, V. Raussens, S. A. Contera, D. T. Rijkers, R. M. Liskamp, J. M. Ruysschaert, J. F. Ryan, F. Separovic, A. Watts, J. Mol. Biol. 2007, 368, 982.

[89] S. D. Zakharov, J. D. Hulleman, E. A. Dutseva, Y. N. Antonenko, J.-C. Rochet, W. A. Cramer, Biochemistry 2007, 46, 14369.

[90] R. Bahadi, P. V. Farrelly, B. L. Kenna, J. I. Kourie, F. Tagliavini, G. Forloni, M. Salmona, Am. J. Physiol. Cell Physiol. 2003, 285, C862.

[91] G. Bainbridge, I. Gokce, J. H. Lakey, FEBS Lett. 1998, 431, 305.

[92] N. Arispe, J. C. Diaz, O. Simakova, Biochim. Biophys. Acta Biomembr. 2007, 1768, 1952.

[93] a) J. Zhong, C. Yang, W. Zheng, L. Huang, Y. Hong, L. Wang, Y. Sha, Biophys. J. 2009, 96, 4610; b) J. Zhong, W. Zheng, L. Huang, Y. Hong, L. Wang, Y. Qiu, Y. Sha, Biochim. Biophys. Acta Biomembr. 2007, 1768, 1420; c) W. Zheng, L. Wang, Y. Hong, Y. Sha, Biochem. Biophys. Res. Commun. 2009, 379, 298.

[94] D. L. Pountney, R. Lowe, M. Quilty, J. C. Vickers, N. H. Voelcker, W. P. Gai, J. Neurochem. 2004, 90, 502.

[95] S. Inoue, Amyloid 2008, 15, 223.

[96] M. Bischofberger, M. R. Gonzalez, F. G. van der Goot, Curr. Opin. Cell Biol. 2009, 21, 589 .

[97] M. R. Gonzalez, M. Bischofberger, L. Pernot, F. G. van der Goot, B. Frêche, Cell. Mol. Life Sci. 2008, 65, 493.

[98] H. Jang, J. Zheng, R. Lal, R. Nussinov, Trends Biochem. Sci. 2008, 33, 91.

[99] a) S. J. Singer, N. N. Dewji, Proc. Natl. Acad. Sci. USA 2006, 103, 1546; b) J. A. Yong, Y. Pin, Chin. Sci. Bull. 2007, 52, 1576.

[100] I. F. Tsigelny, P. Bar-On, Y. Sharikov, L. Crews, M. Hashimoto, M. A. Miller, S. H. Keller, O. Platoshyn, J. X.-J. Yuan, E. Masliah, FEBS J. 2007, 274, 1862.

[101] M. R. R. de Planque, V. Raussens， S. A. Contera， D. T. S. Rijkers, R. M. J. Liskamp, J.-M. Ruysschaert, J. F. Ryan, F. Separovic, A. Watts, J. Mol. Biol. 2007, 368, 982.

[102] R. Kayed, A. Pensalfini, L. Margol, Y. Sokolov, F. Sarsoza, E. Head, J. Hall, C. Glabe, J. Biol. Chem. 2009, 284, 4230.

[103] R. Füssle, S. Bhakdi, A. Sziegoleit, J. Tranum-Jensen, T. Kranz, H. J. Wellensiek, J. Cell Biol. 1981, 91, 83.

[104] A. K. Mahalka, P. K. Kinnunen, Biochim. Biophys. Acta Biomembr. 2009, 1788, 1600.

[105] P. E. Smith, J. R. Brender, A. Ramamoorthy, J. Am. Chem. Soc. 2009, 131, 4470.

[106] E. Y. Chi, S. L. Frey, K. Y. Lee, Biochemistry 2007, 46, 1913.

[107] R. Friedman, R. Pellarin, A. Caflisch, J. Mol. Biol. 2009, 387, 407.

[108] a) A. Jan, O. Gokce, R. Luthi-Carter, H. A. Lashuel, J. Biol. Chem. 2008, 283, 28176; b) M. Wogulis, S. Wright, D. Cunningham, T. Chilcote, K. Powell, R. E. Rydel, J. Neurosci. 2005, 25, 1071.

[109] D. Radovan, N. Opitz, R. Winter, FEBS Lett. 2009, 583, 1439.

[110] L.-M. Yan, A. Velkova, M. Tatarek-Nossol, E. Andreetto, A. Kapurniotu, Angew. Chem. 2007, 119, 1268; Angew. Chem. Int. Ed. 2007, 46, 1246.

[111] S. J. Singer, G. L. Nicolson, Science 1972, 175, 720.

[112] a) M. Vestergaard, T. Hamada, M. Takagi, Biotechnol. Bioeng. 2008, 99, 753; b) L. Maler, A. Graslund, Methods Mol. Biol. 2009, 480, 129 .

[113] Y. H. Chan, S. G. Boxer, Curr. Opin. Chem. Biol. 2007, 11, 581.

[114] L. A. Munishkina, A. L. Fink, Biochim. Biophys. Acta Biomembr. 2007, 1768, 1862. 
[115] A. Fischer, T. Oberholzer, P. L. Luisi, Biochim. Biophys. Acta Biomembr. 2000, 1467, 177.

[116] R. P. Nanga, J. R. Brender, J. Xu, K. Hartman, V. Subramanian, A. Ramamoorthy, J. Am. Chem. Soc. 2009, 131, 8252.

[117] D. J. Schibli, L. T. Nguyen, S. D. Kernaghan, O. Rekdal, H. J. Vogel, Biophys. J. 2006, 91, 4413.

[118] S. V. Dvinskikh, U. H. Durr, K. Yamamoto, A. Ramamoorthy, J. Am. Chem. Soc. 2007, 129, 794.

[119] M. A. Cooper, A. C. Try, J. Carroll, D. J. Ellar, D. H. Williams, Biochim. Biophys. Acta Biomembr. 1998, 1373, 101.

[120] E. Giannakis, J. Pacifico, D. P. Smith, L. W. Hung, C. L. Masters, R. Cappai, J. D. Wade, K. J. Barnham, Biochim. Biophys. Acta Biomembr. 2008, 1778, 1112.

[121] A. Cruz, J. Pérez-Gil, Methods Mol. Biol. 2007, 400, 439.

[122] M. F. M. Engel, H. Yigittop, R. C. Elgersma, D. T. S. Rijkers, R. M. J. Liskamp, B. de Kruijff, J. W. M. Höppener, J. A. Killian, J. Mol. Biol. 2006, 356, 783.

[123] M. Levy, N. Garmy, E. Gazit, J. Fantini, FEBS J. 2006, 273, 5724.

[124] C. Rossi, J. Chopineau, Eur. Biophys. J. 2007, 36, 955.

[125] R. P. Richter, R. Berat, A. R. Brisson, Langmuir 2006, 22, 3497.

[126] B. A. Cornell, V. L. Braach-Maksvytis, L. G. King, P. D. Osman, B. Raguse, L. Wieczorek, R. J. Pace, Nature 1997, 387, 580

[127] B. Seantier, M.-C. Giocondi, C. Le Grimellec, P.-E. Milhiet, Curr. Opin. Colloid Interface Sci. 2008, 13, 326.

[128] L. Zhang, J. Zhong, L. Huang, L. Wang, Y. Hong, Y. Sha, J. Phys. Chem. B 2008, 112, 8950.

[129] P. Van Gelder, F. Dumas, M. Winterhalter, Biophys. Chem. 2000, 85,153 .

[130] R. Khurana, C. Coleman, C. Ionescu-Zanetti, S. A. Carter, V. Krishna, R. K. Grover, R. Roy, S. Singh, J. Struct. Biol. 2005, 151, 229.

[131] J. M. Rausch, W. C. Wimley, Anal. Biochem. 2001, 293, 258.

[132] S. M. Butterfield, A. Hennig, S. Matile, Org. Biomol. Chem. 2009, 7, 1784

[133] G. Das, P. Talukdar, S. Matile, Science 2002, 298, 1600.

[134] F. Kamp, K. Beyer, J. Biol. Chem. 2006, 281, 9251.

[135] R. H. Ashley, T. A. Harroun, T. Hauss, K. C. Breen, J. P. Bradshaw, BMC Struct. Biol. 2006, 6, 21.

[136] a) G. E. Fanucci, D. S. Cafiso, Curr. Opin. Struct. Biol. 2006, 16, 644; b) M. Margittai, R. Langen, Methods Enzymol. 2006, 413, 122 ; c) W. L. Hubbell, A. Gross, R. Langen, M. A. Lietzow, Curr. Opin. Struct. Biol. 1998, 8, 649.

[137] S. M. Raja, S. S. Rawat, A. Chattopadhyay, A. K. Lala, Biophys. J. 1999, 76, 1469.

[138] A. Chattopadhyay, H. Raghuraman, Curr. Sci. 2004, 87, 175.

[139] A. S. Ladokhin, Biophys. J. 1993, 64, A290.

[140] A. K. Ghosh, R. Rukmini, A. Chattopadhyay, Biochemistry 1997, 36, 14291.

[141] C. Montagner, A. Perier, S. Pichard, G. Vernier, A. Menez, D. Gillet, V. Forge, A. Chenal, Biochemistry 2007, 46, 1878.

[142] a) C. Ege, K. Y. Lee, Biophys. J. 2004, 87, 1732; b) V. Vie, N. Van Mau, L. Chaloin, E. Lesniewska, C. Le Grimellec, F. Heitz, Biophys. J. 2000, 78, 846; c) D. Gidalevitz, Y. Ishitsuka, A. S. Muresan, O. Konovalov, A. J. Waring, R. I. Lehrer, K. Y. Lee, Proc. Natl. Acad. Sci. USA 2003, 100, 6302.

[143] a) M. Bak, R. P. Bywater, M. Hohwy, J. K. Thomsen, K. Adelhorst, H. J. Jakobsen, O. W. Sorensen, N. C. Nielsen,
Biophys. J. 2001, 81, 1684; b) A. Naito, T. Nagao, K. Norisada, T. Mizuno, S. Tuzi, H. Saito, Biophys. J. 2000, 78, 2405.

[144] a) E. S. Salnikov, M. De Zotti, F. Formaggio, X. Li, C. Toniolo, J. D. O'Neil, J. Raap, S. A. Dzuba, B. Bechinger, J. Phys. Chem. B 2009, 113, 3034; b) B. Bechinger, D. A. Skladnev, A. Ogrel, X. Li, E. V. Rogozhkina, T. V. Ovchinnikova, J. D. O’Neil, J. Raap, Biochemistry 2001, 40, 9428.

[145] J. Dittmer, L. Thogersen, J. Underhaug, K. Bertelsen, T. Vosegaard, J. M. Pedersen, B. Schiott, E. Tajkhorshid, T. Skrydstrup, N. C. Nielsen, J. Phys. Chem. B 2009, 113, 6928.

[146] L. Yang, T. A. Harroun, T. M. Weiss, L. Ding, H. W. Huang, Biophys. J. 2001, 81, 1475.

[147] C. R. Bodner, C. M. Dobson, A. Bax, J. Mol. Biol. 2009, 390, 775 .

[148] A. Naito, I. Kawamura, Biochim. Biophys. Acta Biomembr. 2007, 1768, 1900.

[149] K. Bertelsen, J. M. Pedersen, B. S. Rasmussen, T. Skrydstrup, N. C. Nielsen, T. Vosegaard, J. Am. Chem. Soc. 2007, 129, 14717.

[150] a) M. Tang, M. Hong, Mol. Biosyst. 2009, 5, 317; b) R. Mani, S. D. Cady, M. Tang, A. J. Waring, R. I. Lehrer, M. Hong, Proc. Natl. Acad. Sci. USA 2006, 103, 16242.

[151] H. Jang, B. Ma, R. Lal, R. Nussinov, Biophys. J. 2008, 95, 4631.

[152] a) F. Yoneyama, Y. Imura, K. Ohno, T. Zendo, J. Nakayama, K. Matsuzaki, K. Sonomoto, Antimicrob. Agents Chemother. 2009, 53, 3211; b) T. Tachi, R. F. Epand, R. M. Epand, K. Matsuzaki, Biochemistry 2002, 41, 10723.

[153] K. Sekiya, R. Satoh, H. Danbara, Y. Futaesaku, J. Bacteriol. 1993, 175, 5953 .

[154] A. Olofsson, H. Hebert, M. Thelestam, FEBS Lett. 1993, 319, 125.

[155] K. He, S. J. Ludtke, D. L. Worcester, H. W. Huang, Biophys. J. 1996, 70, 2659.

[156] M. Han, Y. Mei, H. Khant, S. J. Ludtke, Biophys. J. 2009, 97, 164.

[157] D. O. Mak, W. W. Webb, Biophys. J. 1995, 69, 2323.

[158] E. S. Salnikov, H. Friedrich, X. Li, P. Bertani, S. Reissmann, C. Hertweck, J. D. O’Neil, J. Raap, B. Bechinger, Biophys. J. 2009, $96,86$.

[159] A. Pokorny, P. F. Almeida, Biochemistry 2004, 43, 8846

[160] A. Engel, P. Walter, J. Cell Biol. 2008, 183, 181.

[161] R. Jahn, T. Lang, T. C. Südhof, Cell 2003, 112, 519.

[162] a) S. Dante, T. Hauss, A. Brandt, N. A. Dencher, J. Mol. Biol. 2008, 376, 393; b) T. Pillot, M. Goethals, B. Vanloo, C. Talussot, R. Brasseur, J. Vandekerckhove, M. Rosseneu, L. Lins, J. Biol. Chem. 1996, 271, 28757.

[163] I. Dupiereux, W. Zorzi, L. Lins, R. Brasseur, P. Colson, E. Heinen, B. Elmoualij, Biochem. Biophys. Res. Commun. 2005, $331,894$.

[164] J. Madine, E. Hughes, A. J. Doig, D. A. Middleton, Mol. Membr. Biol. 2008, 25, 518 .

[165] a) D. K. Struck, D. Hoekstra, R. E. Pagano, Biochemistry 1981, 20, 4093; b) Y. Gong, Y. Luo, D. Bong, J. Am. Chem. Soc. 2006, $128,14430$.

[166] H. Ellens, J. Bentz, F. C. Szoka, Biochemistry 1985, 24, 3099.

[167] G. J. Gabriel, J. G. Pool, A. Som, J. M. Dabkowski, E. B. Coughlin, M. Muthukumar, G. N. Tew, Langmuir 2008, 24, 12489. 